\title{
Stress signaling from the lumen of the endoplasmic reticulum: coordination of gene transcriptional and translational controls
}

\author{
Randal J. Kaufman ${ }^{1}$ \\ Department of Biological Chemistry and Howard Hughes Medical Institute, The University of Michigan Medical Center, \\ Ann Arbor, Michigan 48109-0650 USA
}

All eukaryotic cells have an extensive membranous labyrinth network of branching tubules and flattened sacs called the endoplasmic reticulum (ER). Approximately one-third of all cellular proteins are translocated into the lumen of the ER where post-translational modification, folding, and oligomerization occurs. The ER provides a unique oxidizing compartment for the folding of membrane and secretory proteins that are destined to the cell surface, as well as for proteins destined to other intracellular organelles, such as lysosomes and the Golgi compartment. Numerous cellular proteins reside within the ER through a mechanism that requires their continuous vesicle-mediated retrieval from post-ER compartments within the early secretory pathway. These ERresident proteins are chaperones and catalysts of protein folding that form a matrix on which newly synthesized proteins attain their final conformation. The ER is also the site of synthesis of cellular lipids and sterols. In addition, the ER is the major signal-transducing organelle within the cell that continuously responds to environmental cues to release calcium. The ER is exquisitely sensitive to alterations in homeostasis, where, upon a variety of different stimuli, signals are transduced from the ER to the cytoplasm and the nucleus to eventually result in adaptation for survival or induction of apoptosis. The immediate response occurs at the translational apparatus, whereas changes in gene expression promote long-term adaptation or apoptotic cell death. Recent evidence supports findings that these signaling pathways influence pathogenesis associated with viral infection and genetic disease. The purpose of this review is to summarize what is presently known about the diversity of molecular signaling mechanisms that coordinate the complex ER stress response at the translational and transcriptional level in yeast and in higher eukaryotic cells.

\section{The ER is a protein-folding compartment}

The ER provides a unique oxidizing environment in which reside numerous protein chaperones facilitate and

E-MAIL kaufmanr@umich.edu; FAX (313) 763-9323. promote the productive folding of proteins and protein complexes despite the presence of high concentrations of protein that would otherwise interfere with productive folding reactions. These chaperones provide two important functions in protein folding (Gething and Sambrook 1992). First, there are proteins such as protein disulfide isomerase (PDI) and cis-trans prolyl isomerase that catalyze protein-folding reactions and increase the rate, without changing the pathway, at which proteins attain their final folded conformation. Second, there are protein chaperones that do not actively catalyze protein folding, but rather maintain proteins in a folding-competent state. These proteins prevent protein-folding intermediates from aggregating and stabilize energetically unfavorable conformations of polypeptides to minimize irreversible dead-end protein misfolding (Dill and Chan 1997). One of the best-characterized examples of this latter class is the immunoglobulin binding protein $\mathrm{BiP}$. BiP was identified as an ER-localized protein that bound to heavy-chain immunoglobulins and inhibited their secretion in the absence of light chains in pre-B lymphocytes (Haas and Wabl 1983). In this manner, BiP prevents the secretion of incompletely assembled immunoglobulins. Independently, BiP was identified as a member of a protein family that is expressed at a high level in virally transformed cells and upon conditions of glucose deprivation (Lee 1987). Because their induced expression was a consequence of glucose deprivation, this protein family was named the glucose-regulated protein family, or GRPs. In the mid-1980s, it was shown that BiP is identical to GRP78 (Munro and Pelham 1986), the 78-kD family member of GRPs that has homology to the cytosolic Hsp70 stress protein.

As a protein-folding compartment the ER is exquisitely sensitive to alterations in homeostasis. Different stimuli signal through several protein kinases to upregulate the protein-folding capacity of the ER. The GRPs proteins are expressed constitutively in all cells and their transcription is induced in response to a number of different stimuli that disrupt ER function. These stresses include calcium depletion from the ER lumen, 
inhibition of asparagine (N)-linked glycosylation, reduction of disulfide bonds, expression of mutant proteins or protein subunits, or overexpression of some wild-type proteins, etc. These family members are now considered an ER stress-specific inducible family of proteins. When protein misfolding occurs and unfolded proteins accumulate and aggregate in the ER, there is a signal that selectively activates transcription of all the genes encoding GRPs as well as other ER-localized proteins such as PDI (Kozutsumi et al. 1988; Dorner et al. 1989). This signal response was appropriately termed the unfolded protein response (UPR). Protein products that are induced by the UPR are summarized in Table 1. Environmental stimuli that activate the UPR are summarized in Table 2.

The GRPs perform diverse roles to maintain ER function and facilitate protein folding. The numerous ER stress-inducible enzymes that catalyze isomerization reactions in protein folding include PDI and PDI-like activities and cis-trans prolyl isomerase (FKBPs). The most well-characterized peptide-binding proteins that chaperone protein folding in the ER are BiP, designated KAR2 in Saccharomyces cerevisiae, and GRP94. BiP displays a weak ATPase activity that is stimulated by peptides that contain hydrophobic amino acids, such as Leu and Phe (Flynn et al. 1991; Blond-Elguindi et al. 1993a). BiP has an ATPase domain in its amino terminus and a peptidebinding domain in its carboxyl terminus that have been modeled on the crystal structures of the heat-shock protein family members Hsc70 and DnaK, respectively (Flaherty et al. 1990; Zhu et al. 1996). BiP interacts tran- siently with exposed hydrophobic patches on proteinfolding intermediates and is thought to prevent their aggregation while maintaining the protein in a foldingcompetent state. BiP interaction ensures that only properly folded and assembled proteins exit the ER compartment, a process known as 'quality control' (Hurtley and Helenius 1989). Although yeast $\mathrm{BiP}$ is also required for protein translocation into the yeast ER lumen (Panzner et al. 1995), compelling evidence for a similar role for mammalian BiP does not exist. However, mammalian $\mathrm{BiP}$ does associate with the translocation apparatus and appears to maintain a permeability barrier before and soon after the initiation of polypeptide translocation into the ER (Hamman et al. 1998). There are three gene encoding members of the DnaJ protein chaperone family, SEC63, SCJ1, and JEM1, that function to increase the rate of ATP hydrolysis by BiP in yeast. SCI1 and JEM1 are induced by the UPR, and defects in these genes activate the UPR (Silberstein et al. 1998). Members of the DnaJ family that are localized to the ER lumen in higher eukaryotic cells have not been identified.

Another polypeptide-binding protein that displays diverse functions is GRP94 or Grp96/endoplasmin, the ER paralog of Hsp90. GRP94 is also found in association with a number of protein-folding intermediates within the ER lumen and is likely to also display chaperone activity (Muresan and Arvan 1997). The amino-terminal region of GRP94 is highly conserved with Hsp90, for which a three-dimensional structure is available (Prodromou et al. 1997). This conserved region serves as the peptide-binding site and displays 'open' and 'closed' con-

Table 1. Genes induced through the UPR

\begin{tabular}{|c|c|c|c|}
\hline Yeast & Mammals & (KDEL) & Function \\
\hline$K A R 2$ & $B i P / G R P 78$ & $\begin{array}{l}\text { HDEL (yeast) } \\
\text { KDEL (human) }\end{array}$ & protein chaperone \\
\hline LHS1 & & HDEL & protein chaperone/KAR2 family \\
\hline ERO1 & & PRVI & oxidoreductase \\
\hline EUG1 & & HDEL & disulfide bond exchange \\
\hline SCJ1 & & KDEL & cofactor for Kar2p \\
\hline JEM1 & & NFGL & cofactor for Kar2p \\
\hline INO1 & & ERLL & inositol biosynthesis \\
\hline OPI3 & & KKNM & phospholipid synthesis \\
\hline CHO1 & & IPKP & phospholipid synthesis \\
\hline PDI1 & $P D I$ & $\begin{array}{l}\text { HDEL (yeast) } \\
\text { KEEL (human) }\end{array}$ & disulfide bond exchange \\
\hline FKB2 & FKBP13 & $\begin{array}{l}\text { KSAA (yeast) } \\
\text { RTEL (human) }\end{array}$ & cis-trans prolyl isomerase \\
\hline$G T$ & & $\begin{array}{l}\text { KKNM (yeast) } \\
\text { REEL (human) }\end{array}$ & glucosylation of unfolded proteins \\
\hline & GRP94 & KDEL & protein chaperone \\
\hline & GRP170 & NDEL & protein chaperone \\
\hline & ERP72 & KEEL & disulfide bond exchange \\
\hline & ERP59 & KDEL & disulfide bond exchange \\
\hline & ERP29 & KEEL & disulfide bond exchange \\
\hline & HSP47 & RDEL & chaperone for collagen \\
\hline & calreticulin & KDEL & retention of mono-glucosylated glycoproteins \\
\hline & CHOP/GADD153 & LHQA & Transcriptional induction \\
\hline
\end{tabular}

The genes that are induced upon activation of the UPR are indicated. The ER-retrieval signals are indicated for the human species, except for GRP170, which is Chinese hamster. GT is present in S. pombe but absent in S. cerevisiae. 
Table 2. Stimuli that activate the UPR, the EOR, and the phosphorylation of eIF-2 $\alpha$

\begin{tabular}{lccc}
\hline Stimulus & UPR & EOR & eIF- $2 \alpha-P$ \\
\hline 2-Deoxyglucose & + & + & + \\
Tunicamycin & + & + & + \\
Heavy metal ions & + & - & + \\
Heavy chain immunoglobulin & & & \\
$\quad$ expression & + & + & N.D. \\
Brefeldin A & + & + & + \\
Dithiothreitol & + & - & + \\
Ca $^{2+}$ ionophores & + & \pm & + \\
Castanospermine & + & - & - \\
Okadaic acid & - & + & + \\
tert-Butlhydroperoxide & + & + & + \\
Cycloheximide & - & + & - \\
TNF $\alpha$ & - & + & + \\
NF-kB/RelA/p65 overexpression & - & + & N.D. \\
Expression of influenza & & & N.D. \\
$\quad$ hemagglutinin & - & + & + \\
$\quad$ Expression of coagulation & & & \\
$\quad$ factor VIII & + & + & +
\end{tabular}

$(+)$ Where the stimulus activates the response; (-) where the stimulus has no effect. (N.D.) Not determined.

formations for peptide binding. The antitumor drug geldanamycin binds the peptide-binding site and inhibits GRP94 function. Therefore, geldanamycin also induces the UPR (Lawson et al. 1998). This conserved domain of GRP94 also has an adenine nucleotide-binding activity, and a very weak ATPase activity (Wearsch and Nicchitta 1997). Peptide binding to GRP94 occurs in an adenine nucleotide-independent manner. It is possible that accessory proteins that bind GRP94 regulate its peptide-binding activity through ATP hydrolysis. GRP94 also functions as a peptide-binding protein to traffic peptide ligands to major histocompatability complex class I molecules that assemble in the ER (Basu and Srivastava 1999).

Two additional GRPs that provide chaperone functions and participate in quality control are calreticulin and the UDP-glucose/glycoprotein glucosyltransferase (UGT). Calreticulin is the major calcium-binding and storage protein in the ER. Calreticulin also functions as a molecular chaperone, in the regulation of gene expression, and in the regulation of cell adhesion (Dedhar 1994; Nigam et al. 1994; Coppolino et al. 1995; Nauseef et al. 1995; Opas et al. 1996; Krause and Michalak 1997). Calreticulin and calnexin are homologous lectin protein chaperones that transiently and selectively bind to overlapping sets of newly synthesized glycoprotein-folding intermediates, thereby preventing their transit through the secretory pathway. In contrast to calreticulin, the expression of calnexin, an integral transmembrane protein, is not known to be regulated by ER stress. On polypeptide translocation into the lumen of the ER, addition of the high mannose-containing oligosaccharide core structure occurs with subsequent removal of the three terminal glucose residues, which is mediated by the action of glucosidases I and II. The monoglucosylated N- linked glycan is an intermediate in the trimming process. Calnexin and calreticulin bind most avidly to monoglucosylated forms of the $\mathrm{N}$-linked core structure and promote folding, delay oligomerization, and prevent degradation of some glycoproteins (Hebert et al. 1995, 1996). Prolonged association with calnexin and calreticulin is observed when proteins are unfolded, misfolded, or unable to oligomerize. Removal of the third glucose from the oligosaccharide core structure correlates with release from calnexin and calreticulin and transport to the Golgi apparatus. It is proposed that the selective binding of unfolded glycoproteins to calnexin and calreticulin is mediated by reglucosylation of the deglucosylated N-linked oligosaccharide. This reglucosylation activity is performed by a GT, another member of the GRP family. The activity of GT is activated by unfolded protein (Trombetta and Parodi 1992). Therefore, only unfolded, mutant, or unassembled proteins are subject to reglucosylation. Reglucosylated proteins can rebind calnexin and/or calreticulin and, in this manner, unfolded proteins are retained in the ER through a cycle of calnexin and calreticulin interaction, glucosidase II activity, and GT activity.

\section{Diversity in signaling from the ER lumen}

In addition to glycoprotein folding and assembly, the ER is also the site for the synthesis of lipids and sterols. In $S$. cerevisiae, the UPR is also activated in response to lipid deprivation. Therefore, the UPR also coordinates the synthesis of lipids and new membrane structures as the demand arises. On sterol deprivation in the ER membrane, a signal is sent to induce transcription of sterol biosynthetic genes that contain a sterol-regulatory element (SRE) in their promoters (for recent review, see Brown and Goldstein 1997). In this case, an ER membrane-bound transcription factor SREBP (SRE-binding protein) is released by sterol-regulated proteolysis and activates genes encoding products that are required for fatty acid and cholesterol biosynthesis. In addition to the UPR, the ER also generates a signal in response to excessive membrane protein traffic through that organelle. This frequently occurs on viral infection, when viral glycoproteins are produced in massive amounts. Under these conditions, the ER sends a signal to activate the transcription factor NF- $\mathrm{kB}$ to induce expression of immune response and pro-inflammatory genes, such as interferons and cytokines. This signaling pathway was termed the ER overload response (EOR; Pahl and Baeuerle 1995). Evidence is accumulating that many diseases result from protein misfoldings in the ER that are due to mutations that disrupt protein folding or alterations in post-translational modifications (Thomas et al. 1995). Under the wide variety of conditions that result in protein misfolding in the ER, the cellular response may be an important component of the pathophysiological process.

The coordinated synthesis of ER membrane and constituent proteins responds to environmental and physiological stimuli, as well as the differentiation state of the 
cell, to expand the functional capacity of the ER. For example, on differentiation of B lymphocytes into immunoglobulin-secreting plasma cells, the ER expands three to fourfold to accommodate the increased immunoglobulin secretion (Wiest et al. 1990). The smooth ER in hepatocytes expands as the enzymes that oxidize and detoxify drugs (such as cytochrome P450, which oxidizes phenobarbitol) are induced to meet their demand. Overproduction of microsomal cytochrome P450Alk1 (P450Alk1) of Candida maltosa in S. cerevisiae activates the UPR to proliferate the ER extensively (Takewaka et al. 1999). Cells that are selected for resistance to cholesterol-lowering drugs that inhibit HMG-CoA reductase, such as compactin, induce the synthesis of HMG-CoA reductase and also coordinately induce an expansion of the smooth ER membrane to promote sterol biogenesis (Masuda et al. 1983).

In addition to changes in the transcriptional machinery, the immediate response to the accumulation of unfolded proteins in the ER occurs at the translational level to inhibit translation initiation, thereby protecting from further accumulation of unfolded proteins, as well as preserving nutrients and energy. This occurs through activation of one or more protein kinases that specifically phosphorylate the $\alpha$ subunit of eukaryotic translation initiation factor 2 (eIF-2 $\alpha$ ). Small increases in the phosphorylation of eIF- $2 \alpha$ immediately inhibit additional initiation events. Finally, under conditions of severe ER stress in higher eukaryotic cells, a signal is generated that induces programmed cell death, apoptosis. However, the molecular signaling mechanisms that link ER stress to downstream caspase activation to execute cell death remain largely unknown. Therefore, in contrast to the yeast UPR, the mammalian UPR is considerably more diverse by induction of both survival and apoptotic responses. The diversity of ER stress responses in higher eukaryotic cells may have evolved from a need for an effective host response to viral infection that includes viral glycoprotein synthesis, folding, and virion assembly.

\section{Protein kinases that signal in response to unfolded protein in the ER}

Over the last couple of years, significant progress was made in elucidating the signal transduction pathways that emanate from the ER. In many respects these pathways are conserved from yeast to humans and are designed to protect from environmental stresses. Two central mediators of the stress response in yeast are the protein kinases Gcn2p and Irelp. Gcn2p is a dedicated eIF- $2 \alpha$ kinase that is specifically activated on amino acid deprivation to induce the translation of a factor that is required for the transcription of genes encoding enzymes required for amino acid biosynthesis. Ire1p is the proximal sensor of the UPR in yeast that also has an endoribonuclease activity (Fig. 1). In contrast, our understanding of the mammalian UPR remains an enigma where many of the hypotheses to be tested rely on paradigms identified in yeast. Recently, two homologs of yeast

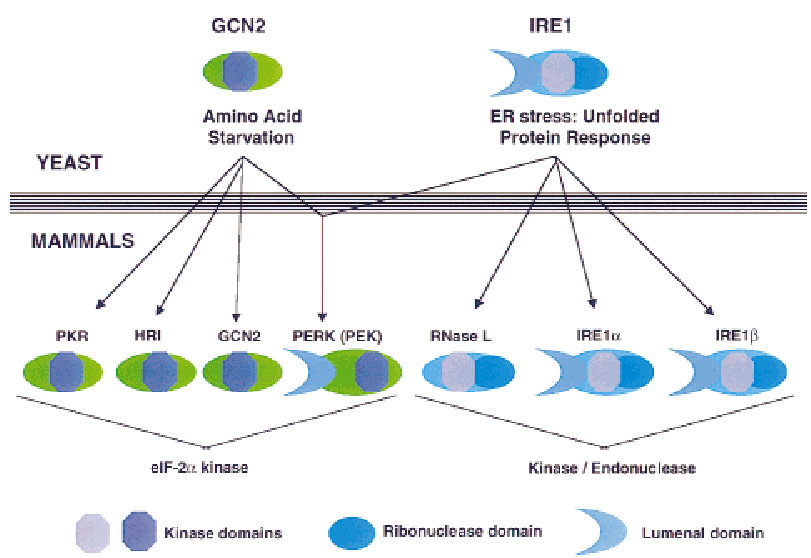

Figure 1. Evolution of stress-response kinases related to $S$. cerevisiae GCN2 and IRE1. The kinase, lumenal, and endoribonuclease domains are depicted as they are organized in these stress-response kinases.

IRE1 were identified that are proposed to sense stress in the ER for transcriptional activation of the GRPs. Another recently discovered ER stress signaling kinase [pancreatic eIF- $2 \alpha$ kinase or PKR-ER-related kinase (PEK/PERK)] has combined the functional properties of yeast Gcn $2 p$ and Ire1p. The sensing lumenal domain of Ire $1 p$ was adjoined to an eIF- $2 \alpha$ kinase domain derived from Gcn $2 p$ to produce an eIF- $2 \alpha$ kinase that specifically responds to ER stress. In addition, the two well-known mechanisms mediating the interferon antiviral response in mammalian cells have possibly evolved from yeast GCN2 and IRE1. The double-stranded (ds) RNA-activated protein kinase PKR has juxtaposed a regulatory dsRNA binding domain to an eIF- $2 \alpha$ kinase so that it is activated in response to dsRNA. The $2{ }^{\prime}-5^{\prime}$ oligoadenylate ribonuclease RNaseL has joined the kinase and endonuclease domain of Ire1p to a regulatory domain that binds 2'-5' oligoadenylates.

\section{The UPR in S. cerevisiae}

Accumulation of unfolded protein in the ER of S. cerevisiae activates a signal transduction pathway that culminates in the transcriptional induction of genes encoding ER-localized protein-folding catalysts and protein chaperones to correct the protein-folding defect by increasing the folding capacity of that compartment (Fig. 2). In addition, this response also activates transcription of genes involved in membrane biosynthesis. Conditions that overload the ER with unfolded and aggregated proteins include the expression of mutant proteins or unassembled protein subunits, overexpression of some wildtype proteins, or treatment with pharmacological agents that disrupt protein folding in the ER, such as tunicamycin to inhibit N-linked glycosylation or $\beta$-mercaptoethanol to inhibit disulfide bond formation. Experimentally, in $S$. cerevisiae as well as in mammalian cells, it also is possible to use conditional lethal temperature-sensitive mutants that have alterations in the ER glycosylation 


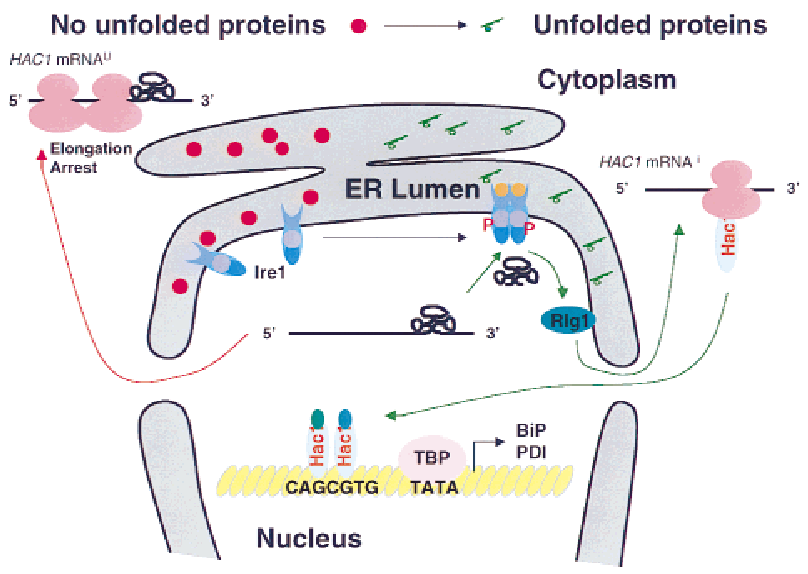

Figure 2. The UPR in S. cerevisiae. On accumulation of unfolded proteins in the ER, Irelp kinase is activated, dimerizes, and trans-phosphorylates itself to elicit endoribonuclease activity. Ire $1 \mathrm{p}$ then cleaves an intron from HAC1 mRNA and Rlg1p subsequently ligates the $5^{\prime}$ and $3^{\prime}$ ends together. This new form of HAC1 mRNA is efficiently translated to produce a protein with 18 new amino acids at the carboxyl terminus (green). Haclp then binds the UPRE and activate genes under UPRE control. The domains of Irelp are as in Fig. 1. The red arrow indicates processes that occur when the UPR is off; the green arrows, processes that occur when the UPR is on.

and/or protein-folding machinery [i.e., tsSec53, which is phosphomannomutase (Kepes and Schekman 1988)]. However, in contrast to mammalian cells, depletion of calcium from the ER does not appear to activate the UPR in S. cerevisiae. Therefore, the mammalian UPR is more sophisticated in responding to a wider variety of stress signals with a wider diversity of downstream effects.

The induction of the ER-resident protein chaperones in response to the accumulation of unfolded protein is regulated at the level of transcription initiation. Analysis of the KAR2 (the S. cerevisiae homolog of mammalian $\mathrm{BiP})$ promoter demonstrated that it was induced in response to both unfolded proteins in the ER and heat shock. These response elements are separable within the KAR2 promoter. A heat-shock element (HSE) resides upstream of a cis-acting 22-bp element, termed the unfolded protein response element (UPRE). The UPRE, and not the HSE, was found upstream from all the genes that respond to the UPR in yeast (Kohno et al. 1993). The UPRE is necessary and sufficient to mediate the transcriptional induction, and mutagenesis studies confirmed the importance of this motif (Mori et al. 1992, 1998). A short consensus sequence within the UPRE is an E-box-like palindrome separated by a single nucleotide spacer (CANCNTG) (Mori et al. 1998). The E-box consensus (CANNTG) is an element that binds transcription factors containing a basic region within their DNA-binding domain.

\section{Ire1p is the proximal sensor for the UPR}

The discovery that the yeast 22-bp UPRE was sufficient for induction of ER chaperones in response to ER stress permitted two groups to isolate mutants in this response by screening for defective UPR-mediated induction of $\beta$-galactosidase under control of a minimal promoter and the 22-bp UPRE. Both groups simultaneously isolated the same gene, IRE1/ERN1 (for inositol requiring and ER to nucleus signaling), that was originally identified as a gene required for inositol prototrophy (Nikawa and Yamashita 1992; Cox et al. 1993; Mori et al. 1993). Cells that lack IRE1 are viable under normal growth conditions but are sensitized and die upon accumulation of unfolded protein in the ER. Cells that lack IRE1 cannot induce the UPR, therefore, the UPR provides a protective mechanism in response to ER stress. IRE1 encodes a 1115-amino-acid polypeptide that has an amino-terminal signal peptide, a unique amino-terminal domain (amino acids 1-526) that is localized to the ER lumen, a short transmembrane domain (amino acids 527-555) that spans the ER membrane, and a carboxy-terminal domain (amino acids 556-1115). The carboxy-terminal domain could reside in the cytoplasm or the nucleoplasm because the ER membrane is continuous with the nuclear envelope. The cytosolic domain has the conserved 12 subdomains and invariant residues present in Ser/Thr protein kinases (Hanks and Hunter 1995). The carboxyl terminus has homology to the ribonuclease domain of mammalian RNaseL. The domain structure of Irelp resembles that of type I growth factor receptors that are activated by ligand-mediated oligomerization and trans-autophosphorylation. Indeed, oligomerization and trans-autophosphorylation are required for activation of Irelp in vitro and in vivo (Shamu and Walter 1996; Welihinda and Kaufman 1996).

\section{Hac1p, a basic leucine zipper transcription factor that activates the yeast UPR}

Genetic strategies were used by three groups independently to isolate Haclp as the trans-acting factor that binds the UPRE (Cox and Walter 1996; Mori et al. 1996; Nikawa et al. 1996). HAC1 was originally isolated as a multicopy suppressor of a cdc10 mutant of Schizosaccharomyces pombe and was proposed to be a basic leucine zipper (bZIP) transcription factor with homology to the activating transcription factor $(\mathrm{ATF}) / \mathrm{cAMP}$-response element (CRE) binding protein (Nojima et al. 1994). It is now known that Haclp is a bZIP protein that binds the UPRE E-box motif upon ER stress (Cox and Walter 1996; Mori et al. 1996). Haclp has a DNA-binding domain and leucine zipper in its amino terminus. Because bZIP transcription factors are known to bind DNA as homo- or heterodimers, it is likely that Haclp binds the symmetrical UPRE as a homodimer. Indeed, the yeast two-hybrid system was used to demonstrate that Haclp can dimerize (Nikawa et al. 1996). The carboxyl terminus of Haclp contains a PEST sequence (Pro, Glu, Ser, Thr rich) that might target the protein for ubiquitin conjugation and degradation by the $26 \mathrm{~S}$ proteosome. Yeast carrying a deletion in HAC1 have the same phenotype as those lacking IRE1, being viable but sensitive to accumulation of 
unfolded protein in the ER. Thus, IRE1 and HAC1 are in the same genetic pathway.

Activation of the UPR pathway is dependent on the cellular levels of Haclp. The $\mathrm{T}_{1 / 2}$ of Haclp is short, $\sim 1-2$ $\min$ in $S$. cerevisiae, and does not change on induction of the UPR (Chapman and Walter 1997; Kawahara et al. 1997). However, in the absence of ER stress, Haclp is not detected, although HAC1 mRNA is produced and is present on polysomes. Kawahara et al. (1997) and Cox et al. (1996) demonstrated that a 252-nucleotide 3' untranslated region (3' UTR) within HAC1 mRNA attenuates its own translation. On activation of the UPR, the 252base intron is excised from the $3^{\prime}$ end of the mRNA. Removal of the intron sequence relieves a translation elongation block so that Haclp is synthesized efficiently and accumulates (Chapman and Walter 1997; Kawahara et al. 1997). Interestingly, Chapman and Walter (1997) demonstrated that the HAC1 252-base intron sequence attenuates not only its own translation but also the translation of a heterologous mRNA encoding green fluorescent protein (GFP) when placed behind the GFPcoding region within the $3^{\prime}$ UTR of the mRNA. It is not known how the attenuator inhibits translational elongation. Analysis of the intron indicated that it contains extensive secondary structure, possibly analogous to a tRNA, and this might prevent ribosome translocation along the mRNA and force ribosomes to pile up on the mRNA. Alternatively, the attenuator might feed back to directly inhibit elongation by the ribosome or may bind a trans-acting factor that inhibits elongation (Chapman et al. 1998).

The splicing reaction of HAC1 mRNA removes the last 10 amino acids at the carboxyl terminus of Haclp and adds 18 amino acids to yield a 238-amino-acid protein. The 238-amino-acid Haclp displayed a 12-fold greater transcriptional activation than the 230-aminoacid form of the protein (Kawahara et al. 1997). The additional 18 residues inserted contain acidic amino acids and two potential serine phosphorylation sites that may be responsible for the greater transcriptional activation. Therefore, both the quantity and quality of Haclp control activation from the UPRE.

\section{Ire1p processes $H A C 1$ mRNA by an unprecedented mechanism}

On accumulation of unfolded proteins in the ER, the 252-base translational attenuator in HAC1 mRNA is removed. Sequence analysis of the 252-base intron sequence demonstrated that it did not have characteristics of pre-mRNA substrates. It did not contain the consensus $5^{\prime}$ and $3^{\prime}$ splice site junctions that form base pairs with snRNAs in the spliceosome that are found in precursor mRNAs from $S$. cerevisiae and higher eukaryotes. In addition, it did not require the conventional precursor mRNA processing machinery. Mutations in two spliceosome components $\left(\mathrm{prp} 2^{\mathrm{ts}}\right.$ and $\left.\operatorname{prp} 8^{\mathrm{ts}}\right)$ did not disrupt splicing of HAC1 mRNA (Cox and Walter 1996). tRNA ligase was required in the final step of the HAC1 splicing reaction where the $5^{\prime}$ and $3^{\prime}$ exons are joined (Sidrauski et al. 1996). Finally, mutation of the $5^{\prime}$ splice site prevented its cleavage but did not inhibit cleavage at the $3^{\prime}$ splice site (Cox and Walter 1996). The spliceosome-mediated splicing reaction requires cleavage at the $5^{\prime}$ splice site for cleavage at the $3^{\prime}$ splice site junction. Thus, the characteristics of the splicing reaction were unprecedented.

The carboxy-terminal residues of yeast Irelp have homology to the mammalian ribonuclease RNaseL. RNaseL is a soluble protein of the cytosol that contains 9 ankrin repeats at its amino terminus followed by a Ser/Thr kinase domain, with the ribonuclease catalytic site at the carboxy-terminal tail. RNaseL is a component of the interferon antiviral response (Player and Torrence 1998). On viral infection, dsRNA is generated as an intermediate in viral replication cycles. dsRNA activates $22^{\prime}-5$ ' oligoadenylate synthetase to generate $2{ }^{\prime}-5^{\prime}$ oligoadenylate polymers. The $2^{\prime}-5^{\prime}$ oligo(A) polymers bind to the seventh and eighth ankrin repeats of RNaseL and induce oligomerization with subsequent activation of its nonspecific ribonuclease activity. Although RNaseL does not exhibit kinase activity, it does require the lysine that coordinates ATP in kinase subdomain 2 for functional RNase activity. Deletion studies support that the carboxy-terminal region of RNaseL contains the catalytic domain and the amino terminus may negatively regulate RNaseL activity in the absence of $2^{\prime}-5^{\prime}$ oligoA (Dong and Silverman 1997).

Given the similarity in sequence and possible mechanism of activation between RnaseL and Irelp, Sidrauski and Walter (1997) tested whether yeast Irelp has an endonuclease activity. They demonstrated that yeast Ire1p is the endoribonuclease that cleaves HAC1 mRNA at the $5^{\prime}$ and $3^{\prime}$ splice sites within the $3^{\prime}$ end of HAC1 mRNA in vitro. The cleaved HAC1 exons are subsequently ligated by the tRNA ligase, Rlg1p (Sidrauski et al. 1996; Sidrauski and Walter 1997). Sidrauski and Walter (1997) successfully reconstituted the IRE1 mRNA splicing reaction in vitro with only two components, Irelp and Rlg1p. Yeast carrying a mutation in RLG1 (rlg1-100, a His-to-Tyr mutation at residue 148) are able to cleave HAC1 mRNA but are defective in the ligation step. Interestingly, this missense mutation only affects HAC1 mRNA ligation, whereas its ligase activity for tRNA splicing is not affected, supporting that different proteinRNA contacts are required for the different reactions (Sidrauski and Walter 1997).

Structural predictions of the HAC1 mRNA intron and flanking sequence identified that the $5^{\prime}$ and $3^{\prime}$ cleavage site both have stem structures with seven-membered loops. Indeed, synthetic oligonucleotides comprising only the stem-loop structures act as substrates for Irelpmediated cleavage in vitro (T.N. Gonzalez, C. Sidrauski, S. Doerfler, and P. Walter, in prep.). Mutagenesis studies demonstrated that the cleavage was sequence specific and either cleavage could occur independently of the other (Kawahara et al. 1998). It was possible to swap the $5^{\prime}$ and $3^{\prime}$ splice site junctions and retain cleavage specificity, although the resultant exons were not ligated by Rlglp (Kawahara et al. 1998). It was proposed that the 5' 
and $3^{\prime}$ splice sites are juxtaposed in the final folded preHAC1 mRNA and that each subunit of a Ire1p homodimer cleaves at one of the sites /Chapman et al. 1998). Given the simplicity of the splicing reaction and the minimal RNA sequence requirements to mediate splicing, it was surprising that when the HAC1 intron was placed within the $3^{\prime}$ end of GFP mRNA, it was not excised upon accumulation of unfolded proteins in the ER (Chapman and Walter 1997). Therefore, this substrate was in a conformation that could not be recognized by Irelp or did not have access to activated Ire1p. This observation suggests that there is more complexity to the reaction and that other factor(s) may be required to position the RNA substrate or otherwise facilitate the Ire1p-mediated splicing reaction in vivo.

\section{Additional modifiers of the UPR: SAGA and PTC2}

The yeast two-hybrid system was used to identify downstream effectors of Irelp (Welihinda et al. 1997). In this screen, GCN5 was identified as a specific interactor with the cytosolic domain of Irelp. In eukaryotes, activation of transcription requires functional interaction between basal factors that occupy the TATA box and the activators that bind the upstream activating sequences. It is thought that this functional interaction is mediated by the transcriptional coactivators. Gcn5p (Ada4p) is a component of a multimeric transcription coactivator complex SAGA that is composed of Ada1p, Ada2p, Ada3p, Ada5p/Spt20p, Spt3, and Spt7 /Georgakopoulos and Thireos 1992; Marcus et al. 1994; Horiuchi et al. 1995; Marcus et al. 1996; Grant et al. 1997). Gcn5p is an acetyltransferase that facilitates transcription by acetylating histone to relax chromatin structures (Brownell et al. 1996). Ada5p and Ada2p are known to functionally and/ or physically interact with transcriptional activators containing acidic amino acid-rich patches and with the TATA-binding protein (TBP). Yeast strains lacking Gcn5p, Ada2p, or Ada3p were partially defective in activating transcription from both a lac Z reporter construct under control of the UPRE and the endogenous KAR2 gene (Welihinda et al. 1997). In contrast, strains carrying deletions in Ada5p were completely defective for the UPR, indicating a strict requirement for Ada5p in this response. However, heat shock-mediated induction of KAR2, from the HSE upstream of the UPRE, was intact in all of these deletion strains (Welihinda et al. 1997). These results demonstrate that there was not a general defect in transcriptional induction in the ada5 strain. Therefore, the Gcn5/Ada complex is specifically required for the UPR but not for the heat-shock response at the same promoter. The Gcn5p/Ada2p/Ada3p/Ada5p complex may form a bridge between TBP and Haclp bound to the UPRE, 100 bp upstream from the promoter.

The ire1, hac1, and ada5 null, and the rlg1-100 mutant strains shared common phenotypes being defective in the UPR and requiring inositol for growth. Preliminary in vitro studies suggest that Irelp directly interacts with Ada5p and that Gen5p directly interacts with Hac1p
(A.A. Welihinda and R.J. Kaufman, unpubl.). Therefore, the original interaction detected between Gen5p and Irelp in the yeast two-hybrid system was probably indirect and mediated by endogenous Ada5p. The interaction of Ada5p with Ire1p is particularly interesting because strains deleted in either one have the same phenotype, being sensitive to tunicamycin treatment and inositol auxotrophy. It was surprising that ada5 deletion cells were defective in HAC1 mRNA processing in response to unfolded proteins in the ER (A.A. Welihinda and R.J. Kaufman, unpubl.). This suggests a novel role for this transcriptional coactivator in HAC1 mRNA processing.

The first negative regulator of the UPR, Ptc2p, was also identified using the cytosolic domain of Ire1p as a bait in the yeast two-hybrid system (Welihinda et al. 1998). The Ser/Thr phosphatase Ptc2p is a type 2C phosphatase that specifically binds Irelp. Because there are no known inhibitors for this class of monomeric $\mathrm{Mn}^{2+}$ or $\mathrm{Mg}^{2+}$-dependent phosphatases, very little is known about their function. They appear to downregulate different stress responses, such as the PBS2/HOG1-MAP kinase pathway that is activated in response to osmotic and heat shock (Tsuiki et al. 1988; Maeda et al. 1993, 1994). Ptc2p directly interacts with and dephosphorylates the phosphorylated form of Ire1p. In contrast, Ptc $2 p$ does not interact with unphosphorylated Irelp, providing a mechanism to dissociate the phosphatase from the kinase once dephosphorylation occurs. Deletion of PTC2 elicited a three to fourfold increase in UPR activity and augmented splicing of HAC1 mRNA, whereas overexpression of Ptc2p downregulated the UPR and attenuated HAC1 mRNA splicing (Welihinda et al. 1998). Therefore, PTC2 negatively regulates the UPR. The activities of the phosphoprotein serine/threonine phosphatase (PPP) family are controlled by a regulatory subunit that localizes the phosphatase to its intracellular site of action (Barford 1996). Because the type 2C phosphatases are monomers, they are not regulated by this mechanism. Ptc $2 p$ has a potential myristic acid addition site at its amino termini and also contains a Irelp interaction domain that may regulate its membrane binding and localization within the cell (Welihinda et al. 1998). Irelp is the first substrate identified for the type 2C Ser/Thr phosphatases and confirms the role of the PTC2 family of phosphatases in stress responses.

\section{Hac1p regulates membrane biogenesis}

In yeast, membrane synthesis is coordinated with the synthesis of ER-resident proteins. Inositol-containing phospholipids are a major constituent of membranes in yeast. Phospholipid synthesis is regulated by the intracellular level of free inositol, where a decrease leads to the transcriptional induction of genes encoding enzymes required for phospholipid biosynthesis. Cox et al. (1997) demonstrated that the UPR is responsible for the coordinated synthesis of membranes and ER stress-induced proteins. A decrease in intracellular free inositol activates Irelp to induce transcription of inositol biosynthetic genes that include inositol-1-phosphate synthase 
(INO1), phospholipid methyltransferase (OPI3), and phosphatidylserine synthase (CHO1). On inositol starvation, either ire1 or hac1, as well as rlg1-100, mutant cells induce much lower levels of INO1 mRNA compared to wild-type cells and, more significantly, do not maintain INO1 mRNA synthesis, providing the basis for the inositol requirement for ire1, hac1, and rlg1-100 mutant strains. This may also provide the basis for the inositol requirement for ada5 deletion cells. In addition, activation of the UPR also induces INO1 transcription in an IRE1- and HAC1-dependent manner. Therefore, the UPR permits the coordinated expansion in both ER volume and protein content during ER stress.

Inositol regulation of membrane synthesis is mediated through a conserved 10-bp element named the UAS INO that is necessary and sufficient for inositol-mediated induction of enzymes required for phospholipid biosynthesis. Expression is regulated through a transcriptional repressor, Opilp (White et al. 1991), another member of the bZIP transcription factor family. opi1 mutant cells constitutively express the enzymes in lipid biosynthesis. Two transcriptional inducers for inositol biosynthetic genes are the bZIP factors, Ino2p and Ino4p, which bind

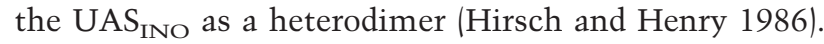
Cells that are double mutant in the UPR and opi1 con-

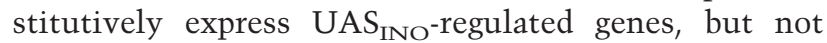
UPRE-controlled genes (Cox et al. 1997). These results indicate that IRE1 and HAC1 are upstream of OPI1 and that the UPR and INO responses diverge downstream of HAC1. Based on these observations, Cox et al. (1997) proposed that the induced form of Haclp (238AA) heterodimerizes with Opilp to titrate out its inhibitory activity. However, to date there are no direct data that show Haclp and Opilp interact.

\section{The mammalian UPR}

Although the signaling mechanisms for the UPR in yeast are well characterized, the mechanisms for signaling the UPR in mammalian cells remain elusive. Based on the similarity of the signaling responses, both being induced by inhibition of N-linked glycosylation or reduction of disulfide bonds in the ER lumen, and both culminating in the transcriptional induction of ER chaperones, it was speculated that a signal transduction mechanism based on an Irelp-like molecule should exist in higher eukaryotes. Indeed, within the last year two IRE1 homologs, $I R E 1 \alpha$ and IRE1 $\beta$, were identified in both human and murine genomes. The cDNAs encoding human hIrel $\alpha \mathrm{p}$ and murine mIre1 $\beta$ p were characterized to show they have characteristics expected for a mammalian IRE1 homolog (Tirasophon et al. 1998; Wang et al. 1998a). The murine and human genetic loci have been termed ern1/ern2 and ERN1/ERN2, respectively. In contrast, a mammalian homolog of yeast HAC1 has not been identified. Thus, at present there appear to be a number of features conserved between $S$. cerevisiae and mammalian species. However, signaling the UPR in mammalian cells is more diverse than in yeast because additional pathways are activated that produce both protective as well as apoptotic responses.

hIre $1 \alpha \mathrm{p}$ is a $110-\mathrm{kD}$ protein that, like its yeast counterpart, is constitutively expressed, but at a very low level. Although the mRNA can be detected in many tissues, it was not possible to detect the endogenous protein (Tirasophon et al. 1998). Interestingly, the mRNA for IRE1 $\alpha$ appears to be autoregulated by a process that requires the kinase and endoribonuclease activities of hIrel $\alpha$ p. Missense mutations within the coding region that disrupt either kinase or endoribonuclease activity increase the level of IRE1 $\alpha$ mRNA by 10 -fold (Tirasophon et al. 1998), leading to the hypothesis that the endonuclease activity of Ire $1 \alpha$ p degrades its own mRNA. In contrast, overexpression of functional hIrel $\alpha \mathrm{p}$ did not appear to autoregulate (Wang et al. 1998a).

hIrel $\alpha$ p contains high-mannose core oligosaccharides, a hallmark of ER-resident glycoproteins. Immunofluorescence studies revealed that hIre $1 \alpha p$ and mIre1 $\beta p$ colocalize with the ER-resident protein chaperones. However, immunofluorescent staining of overexpressed hIrel $\alpha$ p suggested a preferential accumulation of protein around the nucleus. In addition, hIrel $\alpha$ p was shown to colocalize with RanGAP1p, a component of the nuclear pore complex (Tirasophon et al. 1998), suggesting that hIrelp is an ER membrane protein preferentially localized to the nuclear envelope, and possibly the nuclear pore complex. tRNA ligase was previously localized to the yeast nuclear pore complex (Clark and Abelson 1987). The localization of these two mediators of the HAC1 mRNA splicing reaction near the nuclear pore complex suggests that splicing occurs on export of HAC1 mRNA from the nucleus. Consistent with this hypothesis, Walter and colleagues demonstrated that cytosolic unspliced HAC1 mRNA is not spliced upon induction of the UPR (Chapman et al. 1998).

Overexpression of either wild-type hIre $1 \alpha p$ or mIre $1 \beta p$ constitutively activated the UPR, whereas the overexpression of a kinase-defective hIrel $\alpha \mathrm{p}$ mutant downregulated the UPR (Tirasophon et al. 1998; Wang et al. 1998 a). In addition, overexpression of wild-type mIre1 $\beta$ induced apoptosis in the transfected cells (Wang et al. 1998a). Taken together, these data demonstrate that the hIrelp family is required to activate the UPR pathway in mammalian cells and that mIre1 $\beta$ p overexpression and/ or activation is sufficient to induce an apoptotic response.

A mammalian RNA substrate for hIrelp is not presently known. However, it was possible to test the nuclease activity of hIrel $\alpha \mathrm{p}$ in vitro using the yeast HAC1 mRNA as a substrate. Surprisingly, the human protein was able to cleave the $5^{\prime}$ splice site of HAC1 mRNA at the identical site as the yeast Irelp (Tirasophon et al. 1998). The kinase activity of hIrelp was required for the in vitro HAC1 mRNA cleavage, supporting the theory that oligomerization and trans-autophosphorylation precede and are required for endoribonuclease activation. However, previous studies on the yeast Irelp demonstrated that optimal endoribonuclease activity required an adenine nucleotide, and either AMP-PNP or ADP 
stimulated the reaction as well (Sidrauski and Walter 1997). It is possible that the yeast Ire1p protein produced in Escherichia coli was already autophosphorylated and activated upon expression. Therefore, it remains unknown whether adenine nucleotide binding and kinase activity are required to elicit the endoribonuclease activity. It is also possible that the yeast and mammalian Ire1 proteins differ in their mechanism of activation.

Although hIrel $\alpha$ p cleaved the $5^{\prime}$ splice site of HAC1 mRNA, it did not cleave the $3^{\prime}$ splice site (Tirasophon et al. 1998). This indicates an amazing conservation of substrate sequence specificity with also substrate sequence divergence between yeast and human Irelp. Although endoribonuclease activity was not characterized for Ire $1 \beta p$, it was suggested that Ire $1 \beta p$ may cleave the $3^{\prime}$ splice site of yeast $H A C 1 \mathrm{mRNA}$. It was proposed that hIre $1 \beta p$ may interact with Ire $1 \alpha p$ to create a heterodimer capable of cleaving both the $5^{\prime}$ and $3^{\prime}$ splice sites within a putative mammalian HAC1 mRNA substrate (Tirasophon et al. 1998). Although speculative, it is interesting to note that the archeal tRNA endonuclease is a tetramer in which the two homologous catalytic subunits are specific for either the $5^{\prime}$ or $3^{\prime}$ splice site of precursor tRNA molecules (Trotta et al. 1997).

The remarkable conservation of the protein kinase and the RNaseL domains of Irelp between species suggests that both kinase and endoribonuclease activities of hIre $1 \alpha \mathrm{p}$ are critical for transmitting the UPR signal from the ER to the nucleus. The functional requirement for endoribonuclease activity was tested by expression of a hIrel $\alpha \mathrm{p}$ mutant defective in endoribonuclese activity but with intact kinase activity. Overexpression of this hIrel $\alpha$ mutant did not activate the BiP promoter, but rather inhibited induction of the BiP promoter by tunicamycin treatment, when overexpressed in mammalian cells (W. Tirasophon, A.A. Welihinda, and R.J. Kaufman, unpubl.). Therefore, the endoribonuclease activity of hIrel $\alpha \mathrm{p}$ appears to be required for signaling. These observations support the idea that a similar HAC1 mRNAlike processing reaction mediated by the Irelp endonuclease may exist in higher eukaryotes as identified in $S$. cerevisiae. However, it is interesting that on expression of either unspliced or spliced yeast HAC1 mRNA at high level in COS-1 mammalian cells, these mRNAs were translated equally well (D.M. Foti, A.A. Welihinda, R.J. Kaufman, and A.S. Lee, in prep.), indicating that the translational attenuator in the yeast HAC1 intron cannot act in mammalian cells when expressed at a high level. Although differences in growth temperatures between yeast and mammals $\left(30^{\circ} \mathrm{C}\right.$ vs. $\left.37^{\circ} \mathrm{C}\right)$ may affect the structure of $H A C 1 \mathrm{mRNA}$, these results suggest that the mechanism for HAC1 mRNA translational attenuation in mammalian cells may not be identical to that in yeast.

\section{The mammalian UPRE}

The cis-acting promoter element for the mammalian UPR appears significantly more complex than that of $S$. cerevisiae. Studies by Lee and coworkers demonstrated that multiple redundant elements are required. Two critical cis-acting elements identified, CORE and C1, were found to bind the zinc-finger transcription factors YY1 (Li et al. 1997a,b) and the histone-fold motif containing CCAAT-binding transcription factor CBF/NF-Y (Roy and Lee 1995; Roy et al. 1996), respectively. Overexpression of YY1 had little effect on basal expression from the BiP promoter but enhanced induction by ER stress (Li et al. 1997b). However, the binding activity of neither CBF/NF-T nor YY1 changed upon ER stress, suggesting that DNA-binding activity of these factors is not regulated by ER stress. Because transcriptional induction is independent of intracellular calcium influx, it was proposed that UPR induction is mediated by calcium release from the ER (Roy and Lee 1995). More recently, Yoshida et al. (1998) and Roy et al. (1999) noticed that these two elements share a common 19-nucleotide sequence motif $\left[\mathrm{CCAAT}(\mathrm{N}){ }_{9} \mathrm{CCACG}\right]$ with a GC-rich 9-bp spacer. This finding supports the finding that $\mathrm{BiP}$ induction may be mediated by a common mechanism at each element (Yoshida et al. 1998; Roy and Lee 1999). This element was termed the ER stress-response element (ERSE) and evidence supports that it is responsible for the transcriptional induction of $\mathrm{BiP}, \mathrm{GRP} 94$, and calreticulin in response to ER stress (Yoshida et al. 1998). A GCC triplet within the 9-bp spacer was also demonstrated to be required for stress inducibility (Roy and Lee 1999). ERSE1 and ERSE2 in the ERP72 promoter are located within a 82-nucleotide ER protein traffic response element (ERPTRE) identified by Green and coworkers, which is necessary and sufficient for ERP72 induction in response to ER stress (Srinivasan et al. 1993). The ERSE can confer an orientation-independent stress inducibility to a heterologous promoter sequence. The existence of these cis-acting elements provides a mechanism for how the expression of only a limited set of genes is induced to promote protein folding in the ER and relieve ER stress.

Within the rat BiP promoter, ERSE3 (most distal to transcription start site, also called ERSE-163) and ERSE1 (most proximal to transcription start site, also called ERSE-98) are located within the CORE and C1 elements, respectively. In vivo footprinting within the rat $\mathrm{BiP}$ promoter detected ER stress-induced factor occupancy changes within ERSE3 (Li et al. 1994). ERSE3 (GGCCAGCTTG), and neither ERSE1 nor ERSE2, is very similar to the yeast UPRE (GGACAGCGTG). Indeed, overexpression of yeast Haclp, either the 230-amino acid form or the 238-amino acid form, was able to transactivate the rat BiP promoter (D.M. Foti, A.A. Welihinda, R.J. Kaufman, and A.S. Lee, in prep.). It was proposed that activation of the rat BiP promoter by YY1 required a mammalian homolog of yeast Haclp to bind ERSE3. Therefore, the stress regulation would result from alterations in the cellular levels of Haclp. A protein complex, termed ERSF, was recently described that binds ERSEs in a ER stress-inducible manner (Roy and Lee 1999). The identification of the components of this complex should provide insight into the factors that regulate expression from the mammalian ERSE.

Using a yeast one hybrid screening approach, Yoshida et al. (1998) isolated a bZIP protein, ATF6. Although di- 
rect binding of ATF6 to the ERSE was not demonstrated, overexpression of ATF6 constitutively induced the BiP promoter in an ERSE-dependent manner. In nonstressed cells, ATF6 was constitutively expressed as a $90-\mathrm{kD}$ protein (Yoshida et al. 1998). Interestingly, on ER stress the $90-\mathrm{kD}$ protein was post-translationally processed to a 50$\mathrm{kD}$ form that was proposed to be the transcriptionally active form of ATF6. However, there was no detectable change in the level or size of the ATF6 mRNA, suggesting that it is not a substrate for a mammalian Irelp endoribonuclease-like activity. It was proposed that an mRNA encoding an ATF6-processing enzyme might be a substrate for mammalian Ire1p (Yoshida et al. 1998).

\section{Regulation of GRP induction}

Transcriptional activation of ER-resident chaperones provides a protective effect in response to the accumulation of unfolded proteins in the ER. Preventing the induction of GRPs through transfection of BiP antisense RNA expression constructs, transfection of anti-BiP ribozymes, or transfection with multiple copies of the $\mathrm{BiP}$ promoter element to titrate out positively acting transcription factors increased sensitivity to ionophore, oxidative stress, hypoxia, and cell-mediated toxicity (Gomer et al. 1991; Li and Lee 1991; Li et al. 1992; Sugawara et al. 1993; Koong et al. 1994). In contrast, overexpression of $\mathrm{BiP}$ itself prevented transcriptional induction in response to ER stress and protected cells from death in response to calcium depletion from the ER (Dorner et al. 1992; Morris et al. 1997). These studies suggest that BiP acts to alleviate the stress in the ER and/or to prevent generation of a death-inducing signal, presumably by preventing activation of Ire1p.

It is striking that all of the genes, except CHOP/ GADD153 (GEBP homologous protein/growth arrest and DNA damage inducible), that are known to be induced by the UPR in mammalian cells encode ER-resident lumenal proteins that are continuously retrieved from post-ER compartments by the Erd2p receptor (Lewis and Pelham 1990). Erd2p is a multiple-spanning transmembrane protein that is required for retrieval of proteins that escape the ER compartment. Presumably all proteins that are retrieved by the Erd2p receptor contain a tetrapeptide, termed KDEL, at their carboxyl terminus (Table 1). Surprisingly, in higher eukaryotes all of the UPR-induced genes encode proteins that contain a KDEL-like sequence. Therefore, there may be a functional association between the promoter elements for these genes and their carboxy-terminal tetrapeptide retrieval signal. It is interesting to note that erd2 and ire 1 are synthetic lethal in S. cerevisiae (Beh and Rose 1995). The interpretation given to this result was that in the absence of ER retrieval, there is a requirement for induced ER chaperone gene expression. It may also be possible that the KDEL sequence is a negative regulatory ligand for Ire1p.

Transcription of the GRP genes is induced on ER stress, however, their transcription is also regulated by growth factor stimulation or withdrawal (Brewer et al.
1997). During cytokine growth factor depletion, the expression of GRPs was reduced, however the UPR remained intact. The kinetics of activation of GRP gene transcription on growth factor addition was distinct from the UPR, suggesting that two independent signaling pathways exist for GRP induction (Brewer et al. 1997).

\section{The EOR}

There are many similarities between yeast and mammalian cells in signaling ER chaperone induction in response to ER stress. However, signaling from the stressed ER in mammalian cells is considerably more diverse. ER stress signals generated in mammalian cells activates the EOR to induce proinflammatory and immune response gene expression. In addition, signaling the UPR in mammalian cells also activates a unique signal to induce cell death. Recent studies suggest that, on ER stress, there are two death-inducing signals that are generated. One signal is Irelp-mediated transcriptional induction of CHOP/GADD153 and another signal is translational inhibition mediated through phosphorylation of the translation initiation factor eIF-2.

A number of ER stresses activate NF- $\kappa$ B to induce transcription of proinflammatory and immune response genes. However, signaling through NF- $\mathrm{B}$ is distinct from signaling induction of GRPs. For example, overexpression of some wild-type proteins such influenza haemagglutinin induce NF- $\mathrm{B}$ activation but have no effect on the UPR pathway (Liu et al. 1995) (Table 2). This signaling pathway was named EOR because it is activated by accumulation of membrane proteins in the ER. Studies support that overexpression of any transmembrane ER-localized protein will activate the EOR (Meyer et al. 1992; Pahl and Baeuerle 1995, 1996; Pahl et al. 1996). On overexpression of adenovirus E3/19K the protein accumulates in the ER and induces NF-кB. Mutation of the cytoplasmic dilysine ER-retrieval signal at the carboxyl terminus of adenovirus E3/19K permitted transport of the protein to the cell surface and the protein did not accumulate in the ER. This mutant E3/19K did not activate NF- $\kappa$, suggesting that ER retention was required (Pahl et al. 1996). It was proposed that the induction of NF-кB in response to viral glycoprotein expression may represent a physiologically significant antiviral host response.

A number of stimuli that disrupt protein folding, such as 2-deoxyglucose, tunicamycin, calcium ionophores, etc., activate both the UPR and the EOR (Table 2). However, because overexpression of some wild-type proteins or protein subunits also activate the UPR, the acronyms UPR and EOR are misnomers. These two pathways respond to different and overlapping types of ER stress and the common feature for their induction is not known. At least two signal-transducing molecules for the UPR are Ire $1 \alpha p$ and Irel $\beta p$, whereas the signal transducing molecule for the EOR has yet to be identified. Identification of the putative ligand(s) within the ER that activate sig- 
naling of the UPR and/or the EOR should aid in discriminating these signaling pathways.

It is possible to distinguish between the UPR and the EOR by pharmacological intervention. The phosphatase inhibitor okadaic acid potently induces NF-кB, whereas it has no significant effect on UPR induction. Okadaic acid does potentiate the UPR induction observed on depletion of calcium from the ER by thapsigargin treatment (Price et al. 1992). Thapsigargin inhibits the ERlocalized $\mathrm{Ca}^{2+}$-dependent ATPase. The ER generates two second messengers in response to stress: calcium and reactive oxygen intermediates (ROIs). Most evidence supports that calcium release precedes ROI generation. Antioxidants inhibit NF-kB activation by all known inducers, including thapsigargin (Schreck et al. 1992a,b; Pahl and Baeuerle 1996). Thapsigargin treatment induces a secondary rise in ROIs, which is inhibited by calcium chelators, suggesting that calcium release is required for ROI generation (Pahl and Baeuerle 1996). Several mechanisms have been proposed to elicit calcium release and ROI generation in response to the EOR. Overexpression or alteration in membrane proteins may disrupt the ER membrane and permit calcium or glutathione (a weak oxidant) to leak out. Alternatively, membrane alterations may affect the activity of the $\mathrm{Ca}^{2+}$-ATPase to block calcium uptake by the ER. Several oxidases localized to the ER membrane (cyclo-oxygenases, lipoxygenases, cytochrome P450, etc.) produce ROIs as a side product of their peroxidase activities. Peroxidase inhibition by treatment with tepoxalin (Tam et al. 1995) prevented NF- $\mathrm{B}$ activation by thapsigargin but not by phorbol esters or TNF $\alpha$, suggesting that these peroxidase activities are important for the calcium-dependent activation of NF- $\kappa B$ (Pahl and Baeuerle 1996).

$\mathrm{NF}-\mathrm{\kappa B}$ is a heterodimer present in the cytoplasm in an

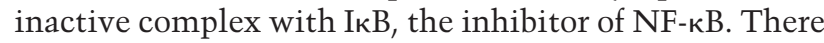
are at least five NF-кB DNA-binding subunits (RelA, RelB, c-Rel, p50, and p52), as well as five IкB proteins that control the activity of NF-кB dimers (ІкB- $\alpha$, ІкB- $\beta$, IкB- $\gamma$, ІкB- $\delta$, and ІкB- $\epsilon$ ) (Baeuerle and Henkel 1994). Exposure of cells to number of stress inducers, such as bacterial or viral infections, ultraviolet- or gamma-irradiation, or proinflammatory cytokines [such as tumor necrosis factor $\alpha(\mathrm{TNF} \alpha)]$, induces the phosphorylation at serine residues 32 and 36 at the amino terminus of ІкB. Phosphorylated ІкB is targeted for ubiquitination and degradation by the $26 \mathrm{~S}$ proteosome, releasing the NF- $\mathrm{KB}$ heterodimer to translocate to the nucleus and activate target genes. Two kinases were identified, IKK $\alpha$ and IKK $\beta$, that heterodimerize and together with NF- $\mathrm{KB}$-inducing kinase (NIK) form a high molecular weight complex of $700-900 \mathrm{kD}$. These kinases form a cascade that is required for IкB phosphorylation and subsequent degradation (Mercurio et al. 1997; Regnier et al. 1997; Woronicz et al. 1997; Zandi et al. 1997). However, it is not known how this kinase complex is activated in response to different stimuli. In addition, the importance of these IкB kinases in signaling the EOR has not been evaluated.

Deletion of the Rel family members in the murine germ line have demonstrated the physiological impor- tance of NF- $\mathrm{kB}$ activation for the proinflammatory response (Baeuerle and Baltimore 1996). For example, mice with c-Rel deletion do not mount effective responses to various pathogens, and immune cells are less responsive for cytokine production. A number of studies support this idea that NF- $\mathrm{kB}$ protects cells from apoptosis (Van Antwerp et al. 1996; C.Y. Wang et al. 1996). Deletion of the RelA (p65) subunit causes early embryonic lethality because of apoptosis in the liver. Mouse embryo fibroblasts derived from RelA knockout mice show enhanced apoptosis in response to TNF $\alpha$ (Beg and Baltimore 1996). Overall, these studies support an antiapoptotic role for $\mathrm{NF}-\mathrm{kB}$ activation in cellular responses.

\section{ER stress-mediated induction of CHOP/GADD153 promotes apoptosis}

As stated earlier, inhibition of N-linked glycosylation or disruption of ER calcium stores leads to programmed cell death, although the mechanism is poorly understood (Larsson et al. 1993; Perez-Sala and Mollinedo 1995). In response to ER stress, the transcription factor $\mathrm{CHOP} /$ GADD153 is induced at the transcriptional level. CHOP was originally identified as a gene induced on DNA damage and growth arrest (Fornace et al. 1988). However, subsequent studies have demonstrated a strong correlation between development of ER stress and induction of CHOP (Bartlett et al. 1992; Chen et al. 1992; Price and Calderwood 1992; Sunnerhagen et al. 1995; Carlberg et al. 1996; Brewer et al. 1997; Dricu et al. 1997). CHOP induction closely parallels the time course of BiP induction, where maximal induction occurs after several hours. The CHOP promoter appears to have less wellconserved ERSE sequences that may function in ERstress transcriptional induction. $C H O P$ is also regulated at the post-translational level by phosphorylation. On phosphorylation on serine residues 78 and 81 by p38 MAP kinase, the transcriptional activation by $\mathrm{CHOP}$ increases (Wang and Ron 1996).

Most evidence supports that $\mathrm{CHOP}$ negatively regulates cell growth and may induce apoptosis. Overexpression of $C H O P$ can lead to cell cycle arrest and apoptosis (Barone et al. 1994; Zhan et al. 1994). Disruption of the CHOP gene by a chromosomal translocation $\mathrm{t}(12$ : 16)(q13:p11) is associated with human myxoid liposarcoma. This translocation results in a fusion between a glycine-rich novel protein and CHOP (Crozat et al. 1993; Rabbitts et al. 1993). Deletion of the CHOP gene in the mouse leads to a modest reduction in cell death on activation of the UPR (Zinszner et al. 1998). Overexpression of $\mathrm{BiP}$ prevented $\mathrm{CHOP}$ induction, suggesting that elevated BiP may attenuate cell death (X.Z. Wang et al. 1996). However, it is not known whether overexpression of BiP relieves ER stress or interferes with UPR signaling (Morris et al. 1997). Transfection studies with hIre $\alpha$ and mIre $\beta$ demonstrate that these signaling molecules can activate $C H O P$ transcription, although the physiological significance of this pathway in $C H O P$ activation is not known. Mice with a homozygous deletion in the $C H O P$ gene displayed reduced apoptosis in renal epithelium in 
response to tunicamycin injection (Zinszner et al. 1998). In addition, there was less subsequent tissue regeneration. These results suggest that CHOP may signal death in response to ER stress and that it may also play a role in cellular regeneration.

CHOP encodes a small nuclear protein that can heterodimerize with C/EBP family members and inhibit C/EBP function (Ron and Habener 1992). Additionally, the CHOP-C/EBP heterodimer can activate downstream target genes (DOCs, for downstream of CHOP). Several genes that respond to $\overline{\mathrm{CHOP}}$ were identified although their significance remains unknown (Wang et al. 1998b; Sok et al. 1999). Murine DOC1 encodes a carbonic anhydrase VI (CA-VI). The stress-inducible form of the gene is expressed from an internal promoter and encodes an intracellular form of what is normally a secreted protein. Studies in $C H O P$ and $C / E B P \beta$ knockout mouse embryo fibroblasts demonstrate that stress-induced expression of CA-VI is both CHOP and $C / E B P \beta$ dependent. A CHOPresponsive element was mapped to the inducible CA-VI promoter, and in vitro footprinting demonstrated that CHOP-C/EBP heterodimers bind to that site. The identification of DOC genes in the ER stress response may identify novel components in the cell death pathway and link ER stress to apoptosis.

\section{Translational control in response to ER stress}

When cells are subjected to ER stress, in addition to transcriptional controls there are immediate changes in the mRNA translational capacity of the cell. Most translational control occurs at the level of initiation. The rate of initiation events on a specific mRNA is dependent on the following: (1) the sequence context of the initiation AUG codon (Kozak 1991a); (2) the presence or absence or upstream open reading frames (ORFs) or of internal ribosomal entry sites (IRESs); (3) the presence of RNA secondary structure upstream of the initiation site; and (4) the sequences within the $5^{\prime}$ and $3^{\prime}$ untranslated regions of the mRNA that might bind translational repressors or activators (Kozak 1991b; Sonenberg 1994; Sachs et al. 1997). The general rate of translation initiation in a cell depends on mRNA abundance, the number of ribosomes, the availability of initiator tRNA ${ }^{\mathrm{Met}}$, and the amount and activity of eukaryotic translation initiation factors (eIFs). Reversible covalent modification of these eIFs is a fundamental mechanism that determines the rate of initiation. The most frequently used mechanisms for translational control are the reversible phosphorylation of eIF$4 \mathrm{E}$ and $\mathrm{eIF}-2$.

eIF-4E is a cap-binding protein that exists free in the cell and also in the eIF-4F complex composed of eIF-4A, eIF-4B, and the large p220 subunit eIF-4G. The activity of eIF-4E is controlled by a set of eIF-4E-binding proteins (a recent review, see Sonenberg and Gingras 1998). The cap binding protein complex eIF-4F promotes ATP-dependent unwinding at the $5^{\prime}$ end of the mRNA. ATP is used by the helicase eIF-4A to facilitate ribosome binding to the $5^{\prime}$ end of the mRNA. Phosphorylation of eIF-4E promotes its ability to bind the 5'-methylguanosine capped structure at the $5^{\prime}$ end of the mRNA and thereby stimulates translation initiation. Regulation of eIF-4E is physiologically important as eIF-4E is present in limiting amounts (0.01-0.2/ribosome) compared with other initiation factors (0.5-3.0/ribosome). Cell stresses such as heat shock and poliovirus infection reduce eIF-4E phosphorylation. In contrast, mitogenic stimuli increase eIF$4 \mathrm{E}$ phosphorylation. Overexpression of eIF-4E transforms NIH-3T3 cells to form tumors in nude mice, supporting a transforming activity for eIF-4E (LazarisKaratzas et al. 1990; Lazaris-Karatzas and Sonenberg 1992). The growth-promoting property of eIF-4E is attributed to the higher eIF-4E requirement for mRNAs that have extensive secondary structure within their 5' UTR. Frequently, mRNAs that have such secondary structure encode growth factors, growth factor receptors, protooncogenes, and other growth-promoting molecules. Some viral RNAs, such as picornaviruses, have evolved a cap-independent mechanism for translation initiation that permits their mRNA to outcompete cellular mRNAs for translation initiation (Gradi et al. 1998). These viruses have an IRES that promotes ribosome binding in the absence of a $5^{\prime}$-methylguanosine-capped structure. Some picornaviruses, such as poliovirus, cleave eIF-4G and inactivate the eIF-4F complex to rapidly prevent cap-dependent translation initiation. Interestingly, some cellular mRNAs also harbor IRES elements and are translated in a cap-independent manner (Rhoads and Lamphear 1995). BiP was identified as an mRNA in poliovirus-infected cells that, in contrast to most cellular mRNAs, continued to be efficiently translated in the presence of cleaved eIF-4G. It is now known that BiP mRNA has an IRES that may provide BiP mRNA the ability to compete for translation under ER stress conditions that limit initiation on other cellular mRNAs (Macejak and Sarnow 1991). However, to date studies have not demonstrated that ER stress alters eIF4F function to elicit preferential BiP mRNA translation.

The second major translational control occurs through phosphorylation of eIF-2, a heterotrimeric protein that is required to bring the initiator $\mathrm{mRNA}^{\mathrm{Met}}$ to the $40 \mathrm{~S}$ ribosome (for review, see Pain 1996). Polypeptide chain synthesis initiates when the ternary complex of eIF-2, GTP, and initiator mRNA ${ }^{\text {Met }}$ binds to the $40 \mathrm{~S}$ ribosomal subunit to generate a $43 \mathrm{~S}$ species. Subsequently, mRNA binds and the 60S ribosomal subunit joins to form the 80 S initiation complex with the concomitant hydrolysis of GTP to GDP. For eIF-2 to promote another round of initiation, GDP bound to eIF-2 must be exchanged for GTP in a reaction catalyzed by the guanine nucleotide exchange factor eIF-2B. Phosphorylation of the $\alpha$ subunit of eIF-2 on serine 51 stabilizes the eIF-2/GDP/eIF-2B complex and prevents the GDP-GTP exchange reaction. Because eIF-2B is required for the exchange of GDP for GTP and because the cellular levels of eIF-2B are approximately one-tenth the levels of eIF-2, the exchange process is inhibited when only a fraction (i.e., 20\%-30\%) of eIF- $2 \alpha$ is phosphorylated and in an inactive complex with eIF-2B. Therefore, phosphorylation of eIF- $2 \alpha$ immediately reduces the level of functional eIF-2 and limits 
initiation events on all cellular mRNAs within the cell. Control through reversible phosphorylation of eIF- $2 \alpha$ provides the cell with an efficient and rapid means to respond to variety of different stimuli.

\section{ER stress signaling through eIF-2 $\alpha$ kinases}

The status of eIF- $2 \alpha$ phosphorylation is controlled by several Ser/Thr protein kinases that are primarily dedicated to recognize eIF- $2 \alpha$ as a substrate. To date, four specific eIF-2 $\alpha$ kinases have been identified in the mammalian genome that are (1) the hemin-regulated inhibitor (HRI) of protein synthesis that is expressed in reticulocytes and is proposed to coordinate globin polypeptide synthesis with hemin availability (Chen 1993); (2) the general control of amino acid biosynthesis kinase (GCN2) that is activated upon amino acid deprivation to paradoxically increase translation of GCN4 mRNA encoding a transcription factor for genes involved in amino acid biosynthesis (Hinnebusch 1996); (3) the PKR that protects cells on viral infection; and (4) the recently identified PEK/PERK (Fig. 3). Original observations demonstrated that on treatment of cells with agents that disrupt ER function, protein synthesis is inhibited, and this correlates with increased eIF- $2 \alpha$ phosphorylation (Prostko et al. 1992) (Table 2). Although all known eIF-2 $\alpha$ kinases are activated by different cellular stress conditions, present evidence supports that PERK, and possibly PKR, respond to stress in the ER.

PERK/PEK was recently identified by two groups independently (Shi et al. 1998; Harding et al. 1999). It is an eIF-2 $\alpha$ kinase that is localized to the ER and has an intralumenal domain that shares limited homology with the lumenal domains of mammalian Ire $1 \alpha$ and Ire1 $\beta$ (Fig. 4). This kinase was demonstrated to phosphorylate eIF$2 \alpha$ at serine 51 in vitro and in vivo (Harding et al. 1999). On overexpression of PERK, the translation of both its

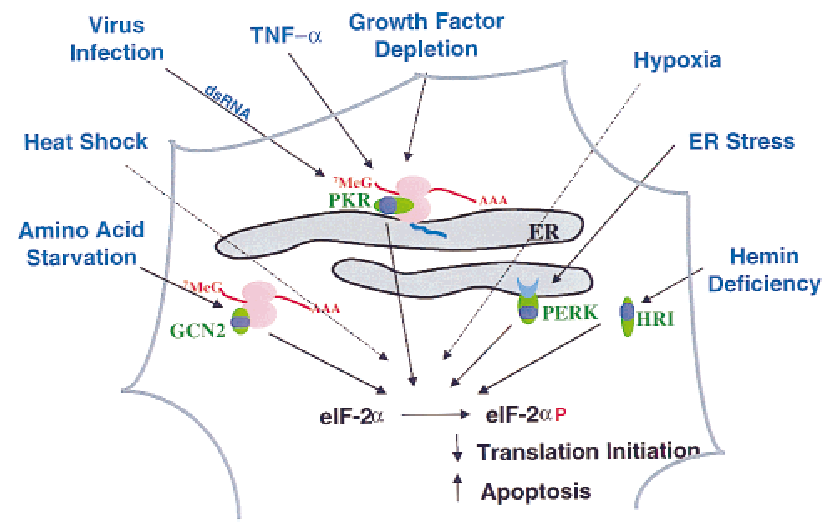

Figure 3. Signaling through eIF- $2 \alpha$ kinases to inhibit protein translation. A variety of stresses activate specific eIF- $2 \alpha$ kinases to elicit an immediate inhibition of translation initiation. Solid arrows indicate stress response pathways where data support that the kinase occurs. Broken arrows represent stresses that activate an eIF- $2 \alpha$ kinase, although the specific kinase has not been studied. The kinase domains are as in Fig. 1.

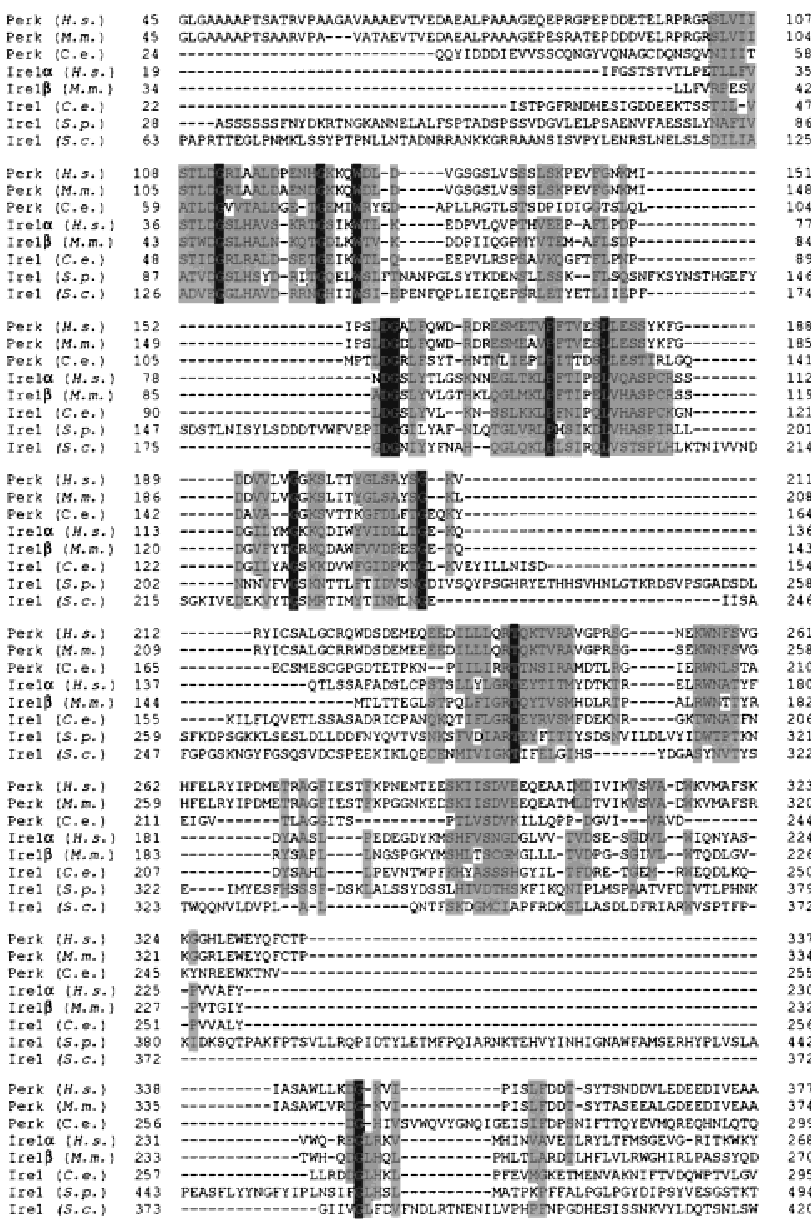

Figure 4. Alignment of the lumenal domains of Ire1p and PERK. Shown are the lumenal domain DNA sequences of cloned PERK cDNAs or genes from human (H.s.) and mouse (M.m.), the putative Perk from C. elegans (C.e.) (Harding et al. 1999), human Ire $1 \alpha$, murine Ire1 $\beta$, Ire1 from $S$. cerevisiae (S.c.), and the putative Ire1 sequences from $C$. elegans and $S$. pombe. (Black) Identical residues; (gray) homologous residues. Dashes represent gaps. Numbers on the left and right represent the position of the first and last amino acid in each lane. The alignment is based on a BLAST search of GenBank with the lumenal domain of human Ire1 $\alpha$.

own mRNA and that of a reporter gene was inhibited. This is consistent with PERK-induced phosphorylation of eIF- $2 \alpha$ and inhibition of mRNA translation. Treatment of cells with tunicamycin or thapsigargin increased autophosphorylation of the overexpressed PERK (Harding et al. 1999). In contrast, treatment with arsenite, heat shock, or UV irradiation did not increase autophosphorylation of PERK. These results support that PERK is an eIF- $2 \alpha$ kinase that is selectively activated on ER stress to prevent further translation. It should be noted that overexpression of $\mathrm{BiP}$ also prevented the ionophore-induced inhibition in protein synthesis, suggesting that BiP overexpression can inhibit signaling through PERK (Morris et al. 1997).

PKR is the interferon-inducible, dsRNA-activated pro- 
tein kinase that is ubiquitously expressed in all mammalian cells (Samuel et al. 1997). PKR is the most studied of the eIF- $2 \alpha$ kinases. It was first identified as a mediator of the antiproliferative and antiviral actions of type 1 interferons. Transcription of PKR is induced upon treatment with interferon $\alpha$ or $\beta$ and the protein is synthesized in a latent form. PKR contains two conserved dsRNA binding motifs in its amino terminus with the eIF- $2 \alpha$ kinase activity in its carboxyl terminus (St. Johnston et al. 1992). A variety of dsRNAs or highly structured RNA molecules generated during viral infection activate PKR from its latent form. On activation, PKR displays two well-known activities: autophosphorylation and phosphorylation of its physiological substrate, the $\alpha$ subunit of eIF-2. As a consequence of PKR activation, viral replication and cell growth are inhibited and cells may undergo differentiation. Increasing evidence supports an additional role for PKR in transcriptional regulation. PKR is implicated in the transcriptional regulation of dsRNA-activated genes such as interferon $\beta$ (Zinn et al. 1988) through activation of the interferon regulatory factor 1 (IRF-1) and NF-кB (Kumar et al. 1994, 1997).

PKR is associated with rough ER membrane, likely through binding to the $60 \mathrm{~S}$ ribosomal subunit in mammalian cells (Jimenez-Garcia et al. 1993; Jeffrey et al. 1995; Wu et al. 1998). This localization suggested that PKR might signal in response to ER stress. However, with the recent identification of PERK, there is a need to re-evaluate the data that implicate PKR in the ER stress response. Studies have detected activated PKR in cells that were treated with calcium ionophores or inhibitors of the calcium-dependent ATPase (Prostko et al. 1995). Expression of a dominant-negative catalytically inactive mutant PKR partially inhibited eIF- $2 \alpha$ phosphorylation and partially protected cells from translational inhibition in response to different stimuli including (1) calcium depletion from the ER mediated by ionomycin, (2) reduction of disulfide bonds mediated by dithiothreitol, and $(3)$ induction of the heat-shock response mediated by sodium arsenite (Prostko et al. 1995; Srivastava et al. 1995). However, it must be considered that interpretations of experiments using dominant-negative mutants are limited as it is not known whether the mutant kinase is affecting the activity of endogenous PKR or another eIF- $2 \alpha$-related kinase. The best data that support a role for PKR in the ER stress response were all obtained from ER stress induced by depletion of ER calcium stores, which may activate several stress signaling pathways. In contrast, there was no effect on ER stress induced translational inhibition in mouse embryo fibroblasts derived from PKR-deficient mice that were treated with either tunicamycin or thapsigargin (Harding et al. 1999; S. Srivastava and R.J. Kaufman, unpubl.). Although the majority of the data support a direct role for PERK in ER stress, it is possible that multiple eIF- $2 \alpha$ kinases may signal in response to separate as well as overlapping ER stresses. Alternatively, the involvement of PKR in ER stress-induced eIF- $2 \alpha$ phosphorylation may be secondary to PERK activation.

\section{Stress-induced eIF-2 $\alpha$ phosphorylation activates apoptosis}

Most studies concerning the role of eIF- $2 \alpha$ phosphorylation in the cellular stress response have been conducted with PKR. Interest in PKR was aroused when the groups of Sonenberg and Hovanessian demonstrated that expression of a catalytically inactive mutant PKR can transform NIH-3T3 cells to form tumors in nude mice (Koromilas et al. 1992; Meurs et al. 1993; Barber et al. 1995). This observation was ascribed to a trans-dominant inhibitory effect of the mutant enzyme on the endogenous wild-type PKR and implicated $P K R$ as a tumor suppressor gene. In addition, overexpression of a nonphosphorylatable Ser51Ala mutant eIF-2 $\alpha$ (Donze et al. 1995), as well as the PKR inhibitors $\mathrm{p} 58^{\mathrm{IPK}}$ and HIV TAR RNA-binding protein (TRBP) also displayed transforming activity (Barber et al. 1994; Benkirane et al. 1997). It was also demonstrated that overexpression of wild-type PKR can inhibit protein synthesis and cell growth in yeast and in mammalian cells (Chong et al. 1992; Thomis and Samuel 1992). A tumor suppressor activity for PKR is consistent with a rearrangement detected in the PKR gene in a lymphocytic leukemia (Abraham et al. 1998). In addition, the 60 S ribosomal protein L18 is a PKR inhibitor that is overexpressed in colorectal cancer tissue (Barnard et al. 1993; Kumar et al. 1999). Subsequently, studies demonstrated that the tumor suppressor activity of PKR could be accounted for by its ability to induce apoptosis when overexpressed and/or activated in mammalian cells (Lee and Esteban 1994; Takizawa et al. 1996; Der et al. 1997). Overexpression of Bcl-2 was able to protect from PKR-induced apoptosis, suggesting that Bcl-2 is downstream of PKR in the apoptotic cascade (Lee et al. 1997).

To elucidate the role of eIF- $2 \alpha$ phosphorylation in PKR-induced apoptosis, studies were performed with a Ser-51-Ala mutant eIF- $2 \alpha$ that is resistant to phosphorylation. Overexpression of the Ser-51-Ala mutant transformed NIH-3T3 cells to form tumors in nude mice, similar to observations with catalytically inactive transdominant-negative mutant PKR (Donze et al. 1995). Expression of this Ser-51-Ala mutant eIF- $\alpha$ also protected NIH-3T3 cells from serum-deprivation- and TNF $\alpha$-induced apoptosis (Srivastava et al. 1998). In addition, expression of a Ser-51-Asp mutant of eIF- $2 \alpha$ was sufficient to inhibit protein synthesis and induce apoptosis in COS-1 cells (Srivastava et al. 1998). Apoptosis in these cells correlated with activation of caspase 3 . These studies demonstrate a role for eIF- $2 \alpha$ phosphorylation in apoptosis under certain conditions. It will be important to determine if overexpression or activation of PERK is sufficient to induce apoptosis. In addition, future studies are required to elucidate how a reduction in protein synthesis initiation can induce an apoptotic cascade. Three possibilities include (1) the translational inhibition of an antiapoptotic gene product, such as an inhibitor of apoptosis (IAP, Deveraux and Reed 1999), (2) a paradoxical preferential translation of an mRNA encoding an effector of apoptosis, similar to translational control of 
GCN4, or (3) a direct feedback from the translational apparatus (i.e., accumulation of free $40 \mathrm{~S}$ ribosomes) directly into the proapoptotic pathway.

Viruses have evolved many gene products that act through different mechanisms to inhibit apoptosis (Shen and Shenk 1995). These mechanisms are vital for viruses to establish their latent states. These antideath mechanisms include modulation of Bcl-2, inactivation of the tumor suppressor p53, and caspase inhibition. PKR was originally identified as a cellular antagonist to viral infections. PKR-mediated inhibition of protein synthesis would directly prevent virus protein production. However, PKR activation also provides additional antiviral activity by limiting viral spread through promoting apoptosis and subsequent autodigestion of the cell. As a consequence, viruses evolved numerous mechanisms to prevent PKR activation leading to apoptosis (Katze 1995). Because it is possible that PERK will be activated by excessive viral glycoprotein expression, it is likely that viruses have evolved mechanisms to prevent PERK activation. The pathogenesis for those viruses that do not have effective means for inactivating PKR and/or PERK may be attributed to viral-induced host-cell apoptosis. If this turns out to be true, then therapeutic intervention to prevent PERK and/or PKR activation may limit certain types of viral pathogenesis.

\section{Potential ligands that activate the Ire1 and/or PERK}

Original comparison of yeast and human Ire1 lumenal domains did not detect any regions of significant homology. With the identification of PERK it is now possible to align the lumenal domains from all the species where they have been characterized (Fig. 4). This alignment significantly suggests that a couple of sequence motifs were very conserved throughout evolution. The homology displayed between the lumenal domains of PERK, Ire $1 \alpha$, and Ire1 $\beta$ suggests they use a similar mechanism to transduce ER stress, and possibly share a similar ligand. Expression of either the isolated lumenal domain of mIre1 $\beta p$ or of PERK alone inhibited transcriptional activation from the CHOP promoter on tunicamycin treatment (Harding et al. 1999). This shows that either the Ire1 $\beta$ or the PERK lumenal domain can interfere with ER signaling for CHOP induction and suggests that both lumenal domains respond to a similar signal on inhibition of glycosylation. It will be interesting to know if PERK and Ire $1 \alpha / \beta$ can trans-activate each other.

Whereas the signals emanating from Ire $1 p$ and the cellular responses generated by them are being illuminated, the molecular events occurring within the ER lumen that activate Ire1p remain largely unknown. It is possible that Irelp and PERK bind to exposed hydrophobic patches on unfolded proteins that are in the process of aggregating, and therefore become oligomerized and activated. It was also proposed that $\mathrm{BiP}$ may negatively regulate Ire1p (Mori et al. 1993). Ire1p may sense the level of free BiP in the ER so that in the absence of unfolded proteins, BiP would be available to bind Ire $1 \mathrm{p}$ and prevent its oligomerization and subsequent activation.
On accumulation of unfolded proteins, BiP would bind unfolded polypeptides allowing Ire1p to oligomerize. BiP is present in the ER in monomeric and oligomeric states. $\mathrm{BiP}$ protein in oligomers is also modified by phosphorylation and ADP ribosylation (Freiden et al. 1992; BlondElguindi et al. 1993b). On accumulation of unfolded protein in the ER, BiP oligomers dissociate and the modifications are removed. It is possible that the status of $\mathrm{BiP}$ oligomerization and/or modification may influence Irelp and/or PERK activation. However, to date there has been no demonstration that BiP actually interacts with Ire1p. A number of experiments suggest that $\mathrm{BiP}$ negatively regulates the UPR. In both yeast (Kohno et al. 1993) and mammalian cells (Malmstrom 1982) overexpression of BiP down-regulates the UPR. Because the BiP ATPase activity was required to down-regulate the UPR (Morris et al. 1997), it can be assumed that cycles of BiP binding and release are required to prevent activation of the UPR. Moreover, reduction of BiP levels is sufficient to induce the UPR (Dorner et al. 1988; Beh and Rose 1995). However, because the level of free BiP inversely correlates with the level of unfolded proteins, these experiments do not provide insight into whether an increase in unfolded protein or a decrease in free BiP elicits UPR activation.

It is intriguing that both Irel $\alpha$ and PERK are most highly expressed in pancreatic tissue (Tirasophon et al. 1998; Shi et al. 1999). The primary function of the pancreas is to respond to blood glucose levels in order to maintain glucose homeostasis through regulation of absorption, gluconeogenesis, and glucose utilization. Immunohistochemical analysis detected PERK expressed only in pancreatic islets of Langerhans, which represent only $1 \%-2 \%$ of the mass of the pancreas. PERK was most highly expressed in the $\delta$ cells of the pancreatic islets, representing $\sim 5 \%$ of the islet cells. The $\delta$ cells secrete somatostatin that regulates release of glucagon and insulin from the $\alpha$ and $\beta$ cells of the islets, respectively. The blood glucose level is the single most important factor that affects protein synthesis and secretion from islet cells. The high-level PERK expression in the $\delta$ cells of the islet might suggest a unique role for PERK in protein synthesis, or perhaps metabolic processes. Alternatively, perhaps the high-level expression is important to rapidly signal changes in blood glucose. The glucosestimulated synthesis of insulin occurs immediately at the level of translation (Goodison et al. 1992; Gilligan et al. 1996). This indicates that if PERK is the primary eIF$2 \alpha$ kinase in this tissue, it should respond to blood glucose levels. The islet cells of the pancreas may also be expected to express high levels of a PERK inhibitor to prevent eIF- $2 \alpha$ phosphorylation and subsequent apoptosis. It is intriguing that the genes that respond to activation of Irelp are also regulated by glucose availability. These observations suggest the possibility that glucose, or a derivative of glucose, may directly activate or prevent activation of the Irel and PERK family of protein kinases. Future experiments should determine whether PERK and/or Irelp is a glucose sensor for the pancreas. 


\section{Protein misfolding in human disease}

It is now known that many genetic diseases are caused by mutations that result in protein misfolding and accumulation within the ER (Thomas et al. 1995) (Table 3). At present it is not known whether any pathology associated with defective protein folding may result from activation of the ER stress responses. However, as the signaling mechanisms that occur on ER stress are elucidated, it will be possible to utilize pharmacological intervention to determine the role of the ER stress response in the pathology of these diseases.

The most common form of cystic fibrosis is due to a mutation $(\Delta 508)$ in the cystic fibrosis transmembrane conductance regulator (CFTR) protein that results in retention of the protein in the ER and eventual degradation by the cytosolic 26S proteosomal machinery (Lukacs et al. 1994; Ward et al. 1995). Cystic fibrosis patients develop progressive, cytokine-mediated inflammatory lung disease that is the major cause of morbidity and mortality (McElvaney et al. 1992). The production of inflammatory cytokines may be a consequence of activation of the EOR.

Homozygous PiZZ $\alpha 1$-antitrypsin $(\alpha 1$-AT) disease affects 1 in 1800 live births and is a well-characterized cause of emphysema/destructive lung disease. A subgroup of affected individuals also develop chronic liver disease and hepatocellular carcinoma. This is the most common genetic cause of liver disease in children. The $\mathrm{Z}$ allele of $\alpha 1$-AT produces an abnormally folded molecule because of a Glu-342-Lys mutation that is retained in the ER and eventually degraded by the cytosolic 26S proteosome (Qu et al. 1996). To study the etiology for the susceptibility to liver disease, a complementation approach was used in which skin fibroblast cell lines from PiZZ individuals with liver disease (susceptible hosts) and from PiZZ individuals without liver disease (protected hosts) were transfected with the PiZZ mutant $\alpha 1$ -

Table 3. Diseases resulting from protein misfolding

\begin{tabular}{|c|c|}
\hline Disease & Protein \\
\hline$\alpha 1$-AT deficiency & $\alpha 1$-antitrypsin \\
\hline Cystic fibrosis & CFTR \\
\hline Alzheimer's disease & presenillins 1 and 2 \\
\hline Congenital hyperthyroid goiter & thyroglobulin \\
\hline $\begin{array}{l}\text { Familial hypercholesterolemia } \\
\text { class } 2\end{array}$ & LDL receptor \\
\hline $\begin{array}{l}\text { Carbohydrate-deficient } \\
\text { glycoprotein syndrome }\end{array}$ & multiple proteins \\
\hline von Willebrand's disease & von Willebrand factor \\
\hline Hemophilia A & coagulation factor VIII \\
\hline Hemophilia B & coagulation factor IX \\
\hline Osteogenesis imperfecta & type I procollagen \\
\hline Scurvy & collagen \\
\hline Marfan syndrome & fibrillin \\
\hline Tay-Sachs disease & $\beta$-hexosaminidase \\
\hline Retinitis pigmentosa & rhodopsin \\
\hline Leprechaunism & insulin receptor \\
\hline Charcot-Marie-tooth type 1A & $\begin{array}{l}\text { peripheral myelin } \\
\text { protein PMP22 }\end{array}$ \\
\hline
\end{tabular}

AT gene. The results demonstrated a delay in the ER degradation of the mutant $\alpha 1$-AT only in the fibroblasts from susceptible hosts. It was proposed that the subset of PiZZ $\alpha 1$-AT-deficient individuals is more susceptible to liver disease because of a second inherited trait that affects degradation of the protein accumulated in the ER (Wu et al. 1994). To study the course of the disease in humans, transgenic mice were obtained that expressed the mutant allele of $\alpha 1-A T$. These animals displayed neonatal hepatitis and accumulation of the mutant $\alpha 1$ AT protein in the ER of hepatocytes (Carlson et al. 1989). These studies suggest that the pathology associated with liver disease results from activation of stress responses that occur as a consequence of mutant protein accumulation in the ER.

Congenital hypothyroid goiter with deficient thyroglobulin is due to mutations in the thyroglobulin gene that result in accumulation of thyroglobulin in the ER of thyroid cells (Medeiros-Neto et al. 1996). Microscopic analysis of the thyroid cells identified microscopically visible distension of the ER, very similar to that observed in mammalian cells that occurs on accumulation of protein in the ER with concomitant activation of the UPR (Dorner et al. 1989). Associated with mutant thyroglobulin retention within the ER was the induction of ER molecular chaperones, consistent with activation of the UPR.

Alzheimer's disease is a slow-onset neurodegenerative disease that is characterized by the deposition of ordered protein aggregates in the brain. The $\beta$-amyloid precursor protein (APP) is processed in the ER to yield two products $A \beta 40$ and $A \beta 42$. The former accumulates in the trans-Golgi, whereas the latter accumulates in the ER. However, it is not known whether these amyloid deposits are the cause or the effect of the neurodegeneration. The expression of several proinflammatory genes is known to be upregulated in late-stage Alzheimer's disease, suggestive of activation of the EOR. Early onset Alzheimer's disease is associated with mutations in one of the two presenillin genes. Cells carrying a mutation in the presenillin 1 gene were hypersensitive to induction of apoptosis by several stimuli (Guo et al. 1997). These observations suggest that mutations in these genes may contribute to amyloid deposition and activation of the UPR.

\section{Concluding remarks}

The diversity of signaling responses from the lumen of the ER in mammalian cells are modeled in Figure 5. Under a variety of different stress conditions that alter protein folding and/or trafficking through the ER, as-yetunknown signals are generated to activate two families of protein kinases. Activation of the eIF- $2 \alpha$ kinase PERK, and possibly PKR, immediately reduces the rate of translation initiation to prevent further accumulation of unfolded protein in the ER. At the same time, an adaptive response is activated through Irelp to induce transcription of genes encoding protective functions that include ER protein chaperones and enzymes required for mem- 


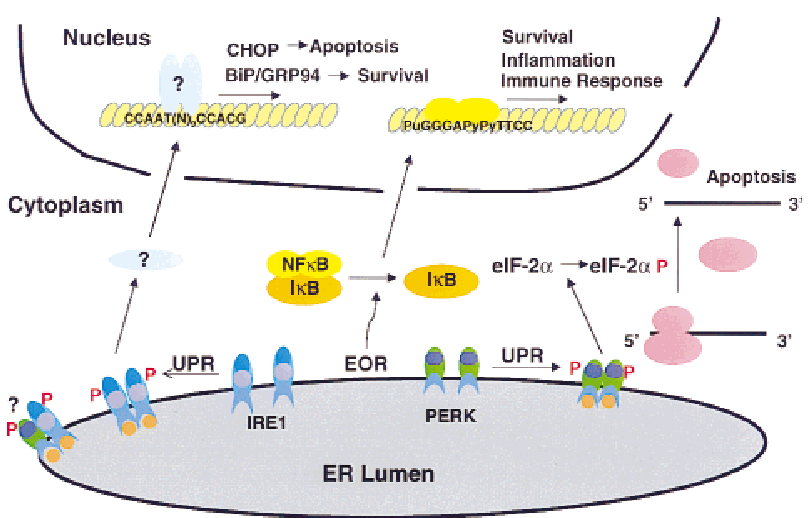

Figure 5. Coordination of translation and transcriptional controls in response to ER stress. On accumulation of unfolded proteins in the ER, Irelp and PERK become activated. Irelp induces the translation of the bZIP transcription factor Haclp. PERK phosphorylates eIF- $2 \alpha$ to inhibit further protein synthesis and prevent further accumulation of unfolded proteins. On activation of the EOR, an as-yet-unknown kinase is activated that phosphorylates ІкB and induces its degradation. Subsequently, the heterodimeric NF- $\mathrm{kB}$ translocates to the nucleus and activates transcription of proinflammatory, immune response, and antiapoptotic genes. The kinase domains are as in Fig. 1.

brane biogenesis. Presumably under conditions of severe ER stress the cell would not be able to adapt and therefore signals are generated to induce apoptosis. Phosphorylation of eIF- $2 \alpha$ initiates an apoptotic signal. In addition, Ire1-mediated induction of CHOP elicits transcriptional activation of downstream genes that may inhibit cells from cycling and also induce apoptosis. In addition, under certain conditions, a signal of unknown nature is generated that activates the transcription factor NF- $\mathrm{KB}$ to induce transcription of genes encoding proinflammatory and immune response functions. NF- $\mathrm{KB}$ induction also generates a protective response from apoptosis. Therefore, a coordinated balance of responses is required to maintain cell survival under conditions of ER stress.

The homology between PERK and IRE1 links ER stress-mediated translational attenuation to the ER stress-mediated transcriptional induction in higher eukaryotes. The lumenal domain acts as a common sensing transducer that is attached to different downstream effectors, that is, eIF- $2 \alpha$ kinase or Ire1p kinase/endoribonuclease. The homologies suggest that evolution has selected for duplication and divergence of these two functions that may have originated in yeast. Mammals have at least one GCN2 homolog; however, they have two IRE1 homologs that likely provide signaling in response to more diverse stimuli in mammalian cells compared to yeast. In addition, the two arms of the mammalian interferon antiviral response, the interferon inducible genes $P K R$ and RNaseL, have possibly evolved from GCN2 and IRE1, respectively. It is surprising that all of the responses to ER stress (the UPR, the EOR, and eIF- $2 \alpha$ phosphorylation) together provide a coordinated antiviral response suggesting that these genes have evolved together specifically to limit viral proliferation in higher eukaryotic cells.

Finally, it is noteworthy to consider that regulation mediated by both GCN2 and IRE1 occurs at the translational level on GCN4 mRNA and HAC1 mRNA to modulate the level of translation of two different bZIP transcription factors that ultimately stimulate protein and membrane biosynthesis in yeast. Gcn2p has a domain that binds uncharged histidyl tRNA and phosphorylates eIF- $2 \alpha$ to increase translation of GCN4 mRNA by permitting read-through of upstream ORFs. In contrast, HAC1 mRNA has a translational attenuator within its 3' UTR that has a structure similar to a tRNA and is removed by Irelp endoribonuclease in a reaction that is not too dissimilar from tRNA splicing. For these responses, control at the level of translation initiation provides a rapid response to ER stress that is not dependent on transcriptional induction.

\section{Acknowledgments}

I thank Yuguang Shi, Amy Lee, Kazutoshi Mori, Wittoon Tirasophon, Martin Schroeder, and Donalyn Scheuner for comments on this review and Martin Schroeder for providing the alignment for the lumenal domains of IRE1 and PERK and Stacey Arnold for compiling the KDEL sequences.

\section{References}

Abraham, N., M.L. Jaramillo, P.I. Duncan, N. Methot, P.L. Icely, D.F. Stojdl, G.N. Barber, and J.C. Bell. 1998. The murine PKR tumor suppressor gene is rearranged in a lymphocytic leukemia. Exp. Cell Res. 244: 394-404.

Baeuerle, P.A. and D. Baltimore. 1996. NF-kappa B: Ten years after. Cell 87: 13-20.

Baeuerle, P.A. and T. Henkel. 1994. Function and activation of NF-к B in the immune system. Annu. Rev. Immunol. 12: $141-179$.

Barber, G.N., S. Thompson, T.G. Lee, T. Strom, R. Jagus, A. Daveau, and M.G. Katze. 1994. The 58-kilodalton inhibitor of the interferon induced ds-RNA activated protein kinase is a tetratricopeptide repeat protein with oncogenic properties. Proc. Natl. Acad. Sci. 91: 4278-4282.

Barber, G.N., M. Wambach, S. Thompson, R. Jagus, and M.G. Katze. 1995. Mutants of the RNA-dependent protein kinase (PKR) lacking double-stranded RNA binding domain I can act as transdominant inhibitors and induce malignant transformation. Mol. Cell. Biol. 15: 3138-3146.

Barford, D. 1996. Molecular mechanisms of the protein serine/ threonine phosphatases. Trends Biochem. Sci. 21: 407-412.

Barnard, G.F., R.J. Staniunas, M. Mori, M. Puder, M.J. Jessop, G.D. Steele Jr., and L.B. Shen. 1993. Gastric and hepatocellular carcinomas do not overexpress the same ribosomal protein messenger RNAs as colonic carcinoma. Cancer Res. 53: 4048-4052.

Barone, M.V., A. Crozat, A. Tabaee, L. Philipson, and D. Ron. 1994. CHOP (GADD153) and its oncogenic variant, TLSCHOP, have opposing effects on the induction of G1/S arrest. Genes \& Dev. 8: 453-464.

Bartlett, J.D., J.D. Luethy, S.G. Carlson, S.J. Sollott, and N.J. Holbrook. 1992. Calcium ionophore A23187 induces expression of the growth arrest and DNA damage inducible CCAAT/enhancer-binding protein (C/EBP)-related gene, 
gadd153. Ca2+ increases transcriptional activity and mRNA stability. J. Biol. Chem. 267: 20465-20470.

Basu, S. and P.K. Srivastava. 1999. Calreticulin, a peptide-binding chaperone of the endoplasmic reticulum, elicits tumorand peptide-specific immunity. J. Exp. Med. 189: 797-802.

Beg, A.A. and D. Baltimore. 1996. An essential role for NF-кB in preventing TNF-alpha-induced cell death. Science 274: 782784.

Beh, C.T. and M.D. Rose. 1995. Two redundant systems maintain levels of resident proteins within the yeast endoplasmic reticulum. Proc. Nat1. Acad. Sci. 92: 9820-9823.

Benkirane, M., C. Neuveut, R.F. Chun, S.M. Smith, C.E. Samuel, A. Gatignol, and K.T. Jeang. 1997. Oncogenic potential of TAR RNA binding protein TRBP and its regulatory interaction with RNA-dependent protein kinase PKR. EMBO J. 16: 611-624.

Blond-Elguindi, S., S.E. Cwirla, W.J. Dower, R.J. Lipshutz, S.R. Sprang, J.F. Sambrook, and M.J. Gething. 1993a. Affinity panning of a library of peptides displayed on the bacteriophages reveals the binding specificity of BiP. Cell 75: 717728.

Blond-Elguindi, S., A.M. Fourie, J.F. Sambrook, and M.J. Gething. 1993b. Peptide-dependent stimulation of the ATPase activity of the molecular chaperone $\mathrm{BiP}$ is the result of conversion of oligomers to active monomers. I. Biol. Chem. 268: 12730-12735.

Brewer, J.W., J.L. Cleveland, and L.M. Hendershot. 1997. A pathway distinct from the mammalian unfolded protein response regulates expression of endoplasmic reticulum chaperones in non-stressed cells. EMBO J. 16: 7207-7216.

Brown, M.S. and J.L. Goldstein. 1997. The SREBP pathway: Regulation of cholesterol metabolism by proteolysis of a membrane-bound transcription factor. Cell 89: 331-340.

Brownell, J.E., J. Zhou, T. Ranalli, R. Kobayashi, D.G. Edmondson, S.Y. Roth, and C.D. Allis. 1996. Tetrahymena histone acetyltransferase A: A homolog to yeast Gen5p linking histone acetylation to gene activation. Cell 84: 843-851.

Carlberg, M., A. Dricu, H. Blegen, G.E. Kass, S. Orrenius, and O. Larsson. 1996. Short exposures to tunicamycin induce apoptosis in SV40-transformed but not in normal human fibroblasts. Carcinogenesis 17: 2589-2596.

Carlson, J., B. Rogers, R. Sifers, M. Finegold, S. Clift, F. Demayo, D. Bullock, and S. Woo. 1989. Accumulation of PiZ $\alpha 1$-antitrypsin causes liver damage in transgenic mice. I. Clin. Invest. 83: 1183-1190.

Chapman, R.E. and P. Walter. 1997. Translational attenuation mediated by an mRNA intron. Curr. Biol. 7: 850-859.

Chapman, R., C. Sidrauski, and P. Walter. 1998. Intracellular signaling from the endoplasmic reticulum to the nucleus. Annu. Rev. Cell Dev. Biol. 14: 459-485.

Chen, J.-J. 1993. Translational regulation in reticulocytes: The role of heme-regulated eIF- $2 \alpha$ kinase. In Translational regulation of gene expression 2 (ed. J. Ilan), pp. 349-372. Plenum Press, New York, NY.

Chen, Q., K. Yu, N.J. Holbrook, and J.L. Stevens. 1992. Activation of the growth arrest and DNA damage-inducible gene gadd 153 by nephrotoxic cysteine conjugates and dithiothreitol. J. Biol. Chem. 267: 8207-8212.

Chong, K.L., L. Feng, K. Schappert, E. Meurs, T.F. Donahue, J.D. Friesen, A.G. Hovanessian, and B.R.G. Williams. 1992. Human p68 kinase exhibits growth suppression in yeast and homology to the translational regulator GCN2. EMBO $\mathrm{T}$. 11: $1553-1562$.

Clark, M.W. and J. Abelson. 1987. The subnuclear localization of tRNA ligase in yeast. J. Cell. Biol. 105: 1515-1526.

Coppolino, M., C. Leung-Hagesteijn, S. Dedhar, and J. Wilkins.
1995. Inducible interaction of integrin $\alpha_{2 \beta 1}$ with calreticulin. J. Biol. Chem. 270: 23132-23138.

Cox, J.S. and P. Walter. 1996. A novel mechanism for regulating activity of a transcription factor that controls the unfolded protein response. Cell 87: 391-404.

Cox, J.S., C.E. Shamu, and P. Walter. 1993. Transcriptional induction of genes encoding endoplasmic reticulum resident proteins requires a transmembrane protein kinase. Cell 73: 1197-1206.

Cox, J.S., R.E. Chapman, and P. Walter. 1997. The unfolded protein response coordinates the production of endoplasmic reticulum protein and endoplasmic reticulum membrane. Mol. Biol. Cell 8: 1805-1814.

Crozat, A., P. Aman, N. Mandahl, and D. Ron. 1993. Fusion of CHOP to a novel RNA-binding protein in human myxoid liposarcoma. Nature 363: 640-644.

Dedhar, S. 1994. Novel functions for calreticulin: Interaction with integrins and modulation of gene expression? Trends Biochem. Sci. 19: 269-271.

Der, S.D., Y.L. Yang, C. Weissmann, and B.R. Williams. 1997. A double-stranded RNA-activated protein kinase-dependent pathway mediating stress-induced apoptosis. Proc. Natl. Acad. Sci. 94: 3279-3283.

Deveraux, Q.L. and J.C. Reed. 1999. IAP family proteins-suppressors of apoptosis. Genes \& Dev. 13: 239-252.

Dill, K.A. and H.S. Chan. 1997. From Levinthal to pathways to funnels. Nat. Struct. Biol. 4: 10-19.

Dong, B. and R.H. Silverman. 1997. A bipartite model of 2-5Adependent RNase L. I. Biol. Chem. 272: 22236-22242.

Donze, O., R. Jagus, A.E. Koromilas, J.W. Hershey, and N. Sonenberg. 1995. Abrogation of translation initiation factor eIF-2 phosphorylation causes malignant transformation of NIH 3T3 cells. EMBO J. 14: 3828-3834.

Dorner, A.J., M.G. Krane, and R.J. Kaufman. 1988. Reduction of endogenous GRP 78 levels improves secretion of a heterologous protein in CHO cells. Mol. Cell. Biol. 8: 4063-4070.

Dorner, A.J., L.C. Wasley, D.G. Bole, and R.J. Kaufman. 1989. Increased synthesis of secreted proteins induces expression of glucose regulated proteins in butyrate treated $\mathrm{CHO}$ cells. J. Biol. Chem. 264: 20602-20607.

Dorner, A.J., L.C. Wasley, and R.J. Kaufman. 1992. Overexpression of GRP78 mitigates stress induction of glucose regulated proteins and blocks secretion of selective proteins in Chinese hamster ovary cells. EMBO J. 11: 1563-1571.

Dricu, A., M. Carlberg, M. Wang, and O. Larsson. 1997. Inhibition of N-linked glycosylation using tunicamycin causes cell death in malignant cells: Role of down-regulation of the insulin-like growth factor 1 receptor in induction of apoptosis. Cancer Res. 57: 543-548.

Flaherty, K.M., C. DeLuca Flaherty, and D.B. McKay. 1990. Three-dimensional structure of the ATPase fragment of a 70K heat-shock cognate protein. Nature 346: 623-628.

Flynn, G.C., J. Pohl, M.T. Flocco, and J.E. Rothman. 1991. Peptide-binding specificity of the molecular chaperone BiP. $\mathrm{Na}$ ture 353: 726-730.

Fornace, A.J., Jr., I. Alamo, Jr., and M.C. Hollander. 1988. DNA damage-inducible transcripts in mammalian cells. Proc. Natl. Acad. Sci. 85: 8800-8804.

Freiden, P.J., J.R. Gaut, and L.M. Hendershot. 1992. Interconversion of three differentially modified and assembled forms of BiP. EMBO I. 11: 63-70.

Georgakopoulos, T. and G. Thireos. 1992. Two distinct yeast transcriptional activators require the function of GCN5 protein to promote normal levels of transcription. $E M B O \mathrm{I}$. 11: 4145-4152.

Gething, M.J. and J. Sambrook. 1992. Protein folding in the cell. 
Nature 355: 33-45.

Gilligan, M., G.I. Welsh, A. Flynn, I. Bujalska, T.A. Diggle, R.M. Denton, C.G. Proud, and K. Docherty. 1996. Glucose stimulates the activity of the guanine nucleotide-exchange factor eIF-2B in isolated rat islets of Langerhans. J. Biol. Chem. 271: 2121-2125.

Gomer, C.J., A. Ferrario, N. Rucker, S. Wong, and A.S. Lee. 1991. Glucose regulated protein induction and cellular resistance to oxidative stress mediated by porphyrin photosensitization. Cancer Res. 51: 6574-6579.

Goodison, S., S. Kenna, and S.J. Ashcroft. 1992. Control of insulin gene expression by glucose. J. Biochem. 285: 563-568.

Gradi, A., Y.V. Svitkin, H. Imataka, and N. Sonenberg. 1998. Proteolysis of human eukaryotic translation initiation factor eIF4GII, but not eIF4GI, coincides with the shutoff of host protein synthesis after poliovirus infection. Proc. Natl. Acad. Sci. 95: 11089-11094.

Grant, P.A., L. Duggan, J. Cote, S.M. Roberts, J.E. Brownell, R. Candau, R. Ohba, T. Owen-Hughes, C.D. Allis, F. Winston, S.L. Berger, and J.L. Workman. 1997. Yeast Gen5 functions in two multisubunit complexes to acetylate nucleosomal histones: Characterization of an Ada complex and the SAGA (Spt/Ada) complex. Genes \& Dev. 11: 1640-1650.

Guo, Q., B. Sopher, K. Furukawa, D. Pham, N. Robinson, G. Martin, and M. Mattson. 1997. Alzheimer's presenilin mutation sensitizes neural cells to apoptosis induced by trophic factor withdrawal and amyloid beta-peptide: Involvement of calcium and oxyradicals. J. Neurosci. 17: 4212-4222.

Haas, I.G. and M. Wabl. 1983. Immunoglobulin heavy chain binding protein. Nature 306: 387-389.

Hamman, B.D., L.M. Hendershot, and A.E. Johnson. 1998. BiP maintains the permeability barrier of the ER membrane by sealing the lumenal end of the translocon pore before and early in translocation. Cell 92: 747-758.

Hanks, S.K. and T. Hunter. 1995. Protein kinases 6. The eukaryotic protein kinase superfamily: Kinase (catalytic) domain structure and classification. FASEB. J. 9: 576-596.

Harding, H.P., Y. Zhang, and D. Ron. 1999. Protein translation and folding are coupled by an endoplasmic reticulum-resident kinase. Nature 397: 271-274.

Hebert, D.N., B. Foellmer, and A. Helenius. 1995. Glucose trimming and reglucosylation determine glycoprotein association with calnexin in the endoplasmic reticulum. Cell 81: 425-433.

- 1996. Calnexin and calreticulin promote folding, delay oligomerization and suppress degradation of influenza hemagglutinin in microsomes. EMBO J. 15: 2961-2968.

Hinnebusch, A. 1996. Translational control of GCN4: Gene specific regulation by phosphorylation of eIF-2. In Translational control (ed. M.B. Mathews, N. Sonenberg, and J.W.B. Hersheyl, pp. 199-244. Cold Spring Harbor Laboratory Press, Cold Spring Harbor, NY.

Hirsch, J.P. and S.A. Henry. 1986. Expression of the Saccharomyces cerevisiae inositol-1-phosphate synthase (INO1) gene is regulated by factors that affect phospholipid synthesis. Mol. Cell. Biol. 6: 3320-3328.

Horiuchi, J., N. Silverman, G.A. Marcus, and L. Guarente. 1995. ADA3, a putative transcriptional adapter, consists of two separable domains and interacts with ADA2 and GCN5 in a trimeric complex. Mol. Cell. Biol. 15: 1203-1209.

Hurtley, S.M. and A. Helenius. 1989. Protein oligomerization in the endoplasmic reticulum. Annu. Rev. Cell. Biol. 5: 277307.

Jeffrey, I.W., S. Kadereit, E.F. Meurs, T. Metzger, M. Bachmann, M. Schwemmle, A.G. Hovanessian, and M.J. Clemens. 1995. Nuclear localization of the interferon-inducible protein ki- nase PKR in human cells and transfected mouse cells. Exp. Cell Res. 218: 17-27.

Jimenez-Garcia, L.F., S.R. Green, M.B. Matthews, and D.L. Spector. 1993. Organization of the double-stranded RNAactivated protein kinase DAI and virus-associated VA RNA1 in adenovirus-2-infected HeLa cells. J. Cell Sci. 106: 11-22.

Katze, M.G. 1995. Regulation of the interferon-induced PKR: Can viruses cope? Trends Microbiol. 3: 75-78.

Kawahara, T., H. Yanagi, T. Yura, and K. Mori. 1997. Endoplasmic reticulum stress-induced mRNA splicing permits synthesis of transcription factor Haclp/Ern4p that activates the unfolded protein response. Mol. Biol. Cell 8: 1845-1862.

. 1998. Unconventional splicing of HAC1/ERN4 mRNA required for the unfolded protein response. Sequence-specific and non-sequential cleavage of the splice sites. J. Biol. Chem. 273: 1802-1807.

Kepes, F. and R. Schekman. 1988. The yeast SEC53 gene encodes phosphomannomutase. J. Biol. Chem. 263: 91559161.

Kohno, K., K. Normington, J. Sambrook, M.J. Gething, and K. Mori. 1993. The promoter region of the yeast KAR2 (BiP) gene contains a regulatory domain that responds to the presence of unfolded proteins in the endoplasmic reticulum. Mol. Cell. Biol. 13: 877-890.

Koong, A.C., E.Y. Chen, A.S. Lee, J.M. Brown, and A.J. Giaccia. 1994. Increased cytotoxicity of chronic hypoxic cells by molecular inhibition of GRP78 induction. Int. I. Radiat. Oncol. Biol. Phys. 28: 661-666.

Koromilas, A.E., S. Roy, G.N. Barber, M.G. Katze, and N. Sonenberg. 1992. Malignant transformation by a mutant of the interferon-inducible double-stranded RNA dependent protein-kinase. Science 257: 1685-1689.

Kozutsumi, Y., M. Segal, K. Normington, M.J. Gething, and J. Sambrook. 1988. The presence of malfolded proteins in the endoplasmic reticulum signals the induction of glucoseregulated proteins. Nature 332: 462-464.

Kozak, M. 1991a. An analysis of vertebrate mRNA sequences: Intimations of translational control. J. Cell. Biol. 115: 887903.

- 1991b. Structural features in eukaryotic mRNAs that modulate the initiation of translation. I. Biol. Chem. 266: 19867-19870.

Krause, K.H. and M. Michalak. 1997. Calreticulin. Cell 88: 439443.

Kumar, A., J. Hague, J. Lacoste, J. Hiscott, and B.R.G. Williams. 1994. Double-stranded RNA-dependent protein kinase activates transcription factor NF-кB by phosphorylating I-кB. Proc. Natl. Acad. Sci. 91: 6288-6292.

Kumar, A., Y.L. Yang, V. Flati, S. Der, S. Kadereit, A. Deb, J. Haque, L. Reis, C. Weissmann, and B.R. Williams. 1997. Deficient cytokine signaling in mouse embryo fibroblasts with a targeted deletion in the PKR gene: Role of IRF-1 and NF-кB. EMBO J. 16: 406-416.

Kumar, K.U., S.P. Srivastava, and R.J. Kaufman. 1999. Doublestranded RNA-activated protein kinase (PKR) is negatively regulated by $60 \mathrm{~S}$ ribosomal subunit protein L18. Mol. Cell Biol. 19: 1116-1125.

Larsson, O., M. Carlberg, and A. Zetterberg. 1993. Selective killing induced by an inhibitor of N-linked glycosylation. J. Cell Sci. 106: 299-307.

Lawson, B., J.W. Brewer, and L.M. Hendershot. 1998. Geldanamycin, an hsp90/GRP94-binding drug, induces increased transcription of endoplasmic reticulum (ER) chaperones via the ER stress pathway. J. Cell Physiol. 174: 170-178.

Lazaris-Karatzas, A. and N. Sonenberg. 1992. The mRNA 5' cap-binding protein, eIF-4E, cooperates with v-myc or ElA in 
the transformation of primary rodent fibroblasts. Mol. Cell. Biol. 12: 1234-1238.

Lazaris-Karatzas, A., K.S. Montine, and N. Sonenberg. 1990. Malignant transformation by a eukaryotic initiation factor subunit that binds to mRNA 5' cap. Nature 345: 544-547.

Lee, A.S. 1987. Coordinated regulation of a set of genes by glucose and calcium ionophore in mammalian cells. Trends Biochem. Sci. 12: 20-24.

Lee, S.B. and M. Esteban. 1994. The interferon-induced doublestranded RNA-activated protein kinase induces apoptosis. Virology 199: 491-496.

Lee, S.B., D. Rodriguez, J.R. Rodriguez, and M. Esteban. 1997. The apoptosis pathway triggered by the interferon-induced protein kinase PKR requires the third basic domain, initiates upstream of Bcl-2, and involves ICE-like proteases. Virology 231: 81-88.

Lewis, M.J. and H.R. Pelham. 1990. A human homolog of the yeast HDEL receptor. Nature 348: 162-163.

Li, A. and A.S. Lee. 1991. Competitive inhibition of a set of endoplasmic reticulum protein genes (GRP78, GRP94, and ERP72) retards cell growth and lowers viability after iionophore treatment. Mol. Cell. Biol. 11: 3446-3453.

Li, L.-J., X. Li, A. Ferrario, N. Rucker, E.S. Liu, S. Wong, C.J. Gomer, and A.S. Lee. 1992. Establishment of a Chinese hamster ovary cell line tht expresses GRP78 antisense transcripts and suppresses A23817 induction of both GRP78 and GRP94. J. Cell Physiol. 153: 575-582.

Li, W.W., L. Sistonen, R.I. Morimoto, and A.S. Lee. 1994. Stress induction of the mammalian GRP78/BiP protein gene: in vivo genomic footprinting and identification of p70CORE from human nuclear extract as a DNA-binding component specific to the stress regulatory element. Mol. Cell. Biol. 14: 5533-5546.

Li, W.W., Y. Hsiung, V. Wong, K. Galvin, Y. Zhou, Y. Shi, and A.S. Lee. 1997a. Suppression of grp78 core promoter element-mediated stress induction by the $\mathrm{dbpA}$ and $\mathrm{dbpB}$ (YB-1) cold shock domain proteins. Mol. Cell. Biol. 17: 61-68.

Li, W.W., Y. Hsiung, Y. Zhou, B. Roy, and A.S. Lee. 1997 b. Induction of the mammalian GRP78/BiP gene by $\mathrm{Ca} 2+$ depletion and formation of aberrant proteins: Activation of the conserved stress-inducible grp core promoter element by the human nuclear factor YY1. Mol. Cell. Biol. 17: 54-60.

Liu, W.M., W.M. Chu, P.V. Choudary, and C.W. Schmid. 1995. Cell stress and translational inhibitors transiently increase the abundance of mammalian SINE transcripts. Nucleic Acids Res. 23: 1758-1765.

Lukacs, G., N. Mohamed, N. Kartner, X. Chang, J. Riordan, and S. Grinstein. 1994. Conformational maturation of CFTR but not its mutant counterpart ( $\triangle F 508)$ occurs in the endoplasmic reticulum and requires ATP. EMBO J. 13: 6076-6086.

Macejak, D.G. and P. Sarnow. 1991. Internal initiation of translation mediated by the $5^{\prime}$ leader of a cellular mRNA. Nature 353: 90-94.

Maeda, T., A.Y. Tsai, and H. Saito. 1993. Mutations in a protein tyrosine phosphatase gene (PTP2) and a protein serine/threonine phosphatase gene (PTC1) cause a synthetic growth defect in Saccharomyces cerevisiae. Mol. Cell. Biol. 13: 54085417.

Maeda, T., S.M. Wurgler-Murphy, and H. Saito. 1994. A twocomponent system that regulates an osmosensing MAP kinase cascade in yeast. Nature 369: 242-245.

Malmstrom, B.G. 1982. Enzymology of oxygen. Annu. Rev. Biochem. 51: 21-59.

Marcus, G.A., N. Silverman, S.L. Berger, J. Horiuchi, and L. Guarente. 1994. Functional similarity and physical association between GCN5 and ADA2: Putative transcriptional adaptors. EMBO J. 13: 4807-4815.

Marcus, G.A., J. Horiuchi, N. Silverman, and L. Guarente. 1996. ADA5/SPT20 links the ADA and SPT genes, which are involved in yeast transcription. Mol. Cell. Biol. 16: 3197-3205.

Masuda, A., M. Kuwano, and T. Shimada. 1983. Ultrastructural changes during the enhancement of cellular 3-hydroxy-3methyl-glutaryl-coenzyme A reductase in a Chinese hamster cell mutant resistant to compactin (ML 236B). Cell Struct. Funct. 8: 309-312.

McElvaney, N., P. Nakamura, C. Birrer, W. Herbert, W. Wong, M. Alphonso, J. Baker, M. Catalano, and R. Crystal. 1992. Modulation of airway inflammation in cystic fibrosis: in vivo suppression of interleukin-8 levels on the respiratory epithelial surface by aerosolization of recombinant secretory leukoprotease inhibitor. J. Clin. Invest. 90: 1296-1301.

Medeiros-Neto, G., P. Kim, E. Yoo, J. Vono, M. Targovik, R. Camargo, S. Hossain, and P. Arvan. 1996. Congenital hypothyroid goiter with deficient thyroglobin. J. Clin. Invest. 98: 2838-2844.

Mercurio, F., H. Zhu, B.W. Murray, A. Shevchenko, B.L. Bennett, J. Li, D.B. Young, M. Barbosa, M. Mann, A. Manning, and A. Rao. 1997. IKK-1 and IKK-2: Cytokine-activated IкB kinases essential for NF-каB activation. Science 278: 860866.

Meurs, E.F., J. Galabru, G.N. Barber, M.G. Katze, and A.G. Hovanessian. 1993. Tumor suppressor function of the interferon-induced double-stranded RNA-activated protein kinase. Proc. Natl. Acad. Sci. 90: 232-236.

Meyer, M., W.H. Caselmann, V. Schluter, R. Schreck, P.H. Hofschneider, and P.A. Baeuerle. 1992. Hepatitis B virus transactivator MHBst: Activation of NF- $\mathrm{kB}$, selective inhibition by antioxidants and integral membrane localization. $E M B O$ J. 11: 2991-3001.

Mori, K., A. Sant, K. Kohno, K. Normington, M.J. Gething, and J.F. Sambrook. 1992. A 22 bp cis-acting element is necessary and sufficient for the induction of the yeast KAR2 (BiP) gene by unfolded proteins. EMBO T. 11: 2583-2593.

Mori, K., W. Ma, M.-J. Gething, and J. Sambrook. 1993. A transmembrane protein with a $\mathrm{cdc} 2^{+} / \mathrm{CDC} 28$-related kinase activity is required for signaling from the ER to the nucleus. Cell 74: 743-756.

Mori, K., T. Kawahara, H. Yoshida, H. Yanagi, and T. Yura. 1996. Signaling from endoplasmic reticulum to nucleus: Transcription factor with a basic-leucine zipper motif is required for the unfolded protein-response pathway. Genes Cells 1: 803-817.

Mori, K., N. Ogawa, T. Kawahara, H. Yanagi, and T. Yura. 1998. Palindrome with spacer of one nucleotide is characteristic of the cis-acting unfolded protein response element in Saccharomyces cerevisiae. J. Biol. Chem. 273: 9912-9920.

Morris, J.A., A.J. Dorner, C.A. Edwards, L.M. Hendershot, and R.J. Kaufman. 1997. Immunoglobulin binding protein (BiP) function is required to protect cells from endoplasmic reticulum stress but is not required for the secretion of selective proteins. J. Biol. Chem. 272: 4327-4334.

Munro, S. and H.R.B. Pelham. 1986. An Hsp 70-like protein in the ER: Identity with the $78 \mathrm{Kd}$ glucose-regulated protein and immunoglobulin heavy chain binding protein. Cell 46: $291-300$.

Muresan, Z. and P. Arvan. 1997. Thyroglobulin transport along the secretory pathway. Investigation of the role of molecular chaperone, GRP94, in protein export from the endoplasmic reticulum. J. Biol. Chem. 272: 26095-26102.

Nauseef, W.M., S.J. McCormick, and R.A. Clark. 1995. Calreticulin functions as a molecular chaperone in the biosynthesis of myeloperoxidase. J. Biol. Chem. 270: 4741-4747. 
Nigam, S.K., A.L. Goldberg, S. Ho, M.F. Rohde, K.T. Bush, and M.Y. Sherman. 1994. A set of endoplasmic reticulum proteins possessing properties of molecular chaperones includes $\mathrm{Ca}^{2+}$ binding proteins and members of the thioredoxin superfamily. J. Biol. Chem. 269: 1744-1749.

Nikawa, J., M. Akiyoshi, S. Hirata, and T. Fukuda. 1996. Saccharomyces cerevisiae IRE2/HAC1 is involved in IRE1-mediated KAR2 expression. Nucleic Acids Res. 24: 4222-4226.

Nikawa, J.I. and S. Yamashita. 1992. IRE1 enclodes a putative protein kinae containing a membrane-spanning domain and is required for inositol phototrophy in Saccharomyces cerevisiae. Mol. Microbiol. 6: 1441-1446.

Nojima, H., S.H. Leem, H. Araki, A. Sakai, N. Nakashima, Y. Kanaoka, and Y. Ono. 1994. Hacl: A novel yeast bZIP protein binding to the CRE motif is a multicopy suppressor for cdc10 mutant of Schizosaccharomyces pombe. Nucleic Acids Res. 22: 5279-5288.

Opas, M., M. Szewczenko-Pawlikowski, G.K. Jass, N. Mesaeli, and M. Michalak. 1996. Calreticulin modulates cell adhesiveness via regulation of vinculin expression. J. Cell. Biol. 135: 1913-1923.

Pahl, H.L. and P.A. Baeuerle. 1995. A novel signal transduction pathway from the endoplasmic reticulum to the nucleus is mediated by transcription factor NF-кB. EMBO J. 14: 2580 2588.

- 1996. Activation of NF-kappa B by ER stress requires both $\mathrm{Ca} 2+$ and reactive oxygen intermediates as messengers. FEBS Lett. 392: 129-136.

Pahl, H.L., M. Sester, H.G. Burgert, and P.A. Baeuerle. 1996. Activation of transcription factor NF-кB by the adenovirus E3/19K protein requires its ER retention. I. Cell. Biol. 132: $511-522$.

Pain, V.M. 1996. Initiation of protein synthesis in eukaryotic cells. Eur. J. Biochem. 236: 747-771.

Panzner, S., L. Dreier, E. Hartmann, S. Kostka, and T.A. Rapoport. 1995. Posttranslational protein transport in yeast reconstituted with a purified complex of Sec proteins and Kar2p. Cell 81: 561-570.

Perez-Sala, D. and F. Mollinedo. 1995. Inhibition of N-linked glycosylation induces early apoptosis in human promyelocytic HL-60 cells. J. Cell Physiol. 163: 523-531.

Player, M.R. and P.F. Torrence. 1998. The 2-5A system: Modulation of viral and cellular processes through acceleration of RNA degradation. Pharmacol. Ther. 78: 55-113.

Price, B.D. and S.K. Calderwood. 1992. Gadd45 and Gadd153 messenger RNA levels are increased during hypoxia and after exposure of cells to agents which elevate the levels of the glucose-regulated proteins. Cancer Res. 52: 3814-3817.

Price, B.D., L.A. Mannheim-Rodman, and S.K. Calderwood. 1992. Brefeldin A, thapsigargin, and $\mathrm{AIF}^{4-}$ stimulate the accumulation of GRP78 mRNA in a cycloheximide dependent manner, whilst induction by hypoxia is independent of protein synthesis. J. Cell Physiol. 152: 545-552.

Prodromou, C., S.M. Roe, R. O’Brien, J.E. Ladbury, P.W. Piper, and L.H. Pearl. 1997. Identification and structural characterization of the ATP/ADP-binding site in the Hsp90 molecular chaperone. Cell 90: 65-75.

Prostko, C.R., M.A. Brostrom, E.M. Malara, and C.O. Brostrom. 1992. Phosphorylation of eukaryotic initiation factor (eIF) $2 \alpha$ and inhibition of eIF-2B in GH3 pituitary cells by perturbants of early protein processing the induce GRP78. J. Biol. Chem. 267: 16751-16754.

Prostko, C.R., J.N. Dholakia, M.A. Brostrom, and C.O. Brostrom. 1995. Activation of the double-stranded RNAregulated protein kinase by depletion of endoplasmic reticular calcium stores. J. Biol. Chem. 270: 6211-6215.
Qu, D., J.H. Teckman, S. Omura, and D.H. Perlmutter. 1996. Degradation of a mutant secretory protein, $\alpha 1$-antitrypsin $Z$, in the endoplasmic reticulum requires proteosome activity. J. Biol. Chem. 271: 22791-22795.

Rabbitts, T.H., A. Forster, R. Larson, and P. Nathan. 1993. Fusion of the dominant negative transcription regulator $\mathrm{CHOP}$ with a novel gene FUS by translocation $\mathrm{t}(12 ; 16)$ in malignant liposarcoma. Nat. Genet. 4: 175-180.

Regnier, C.H., H.Y. Song, X. Gao, D.V. Goeddel, Z. Cao, and M. Rothe. 1997. Identification and characterization of an ІкB kinase. Cell 90: 373-383.

Rhoads, R.E. and B.J. Lamphear. 1995. Cap-independent translation of heat shock messenger RNAs. Curr. Top. Microbiol. Immunol. 203: 131-153.

Ron, D. and J.F. Habener. 1992. CHOP, a novel developmentally regulated nuclear protein that dimerizes with transcription factors C/EBP and LAP and functions as a dominant-negative inhibitor of gene transcription. Genes \& Dev. 6: 439453.

Roy, B. and A.S. Lee. 1995. Transduction of calcium stress through interaction of the human transcription factor CBF with the proximal CCAAT regulatory element of the grp78/ BiP promoter. Mol. Cell. Biol. 15: 2263-2274.

. 1999. The mammalian endoplasmic reticulum stress response element consists of an evolutionarily conserved tripartite structure and interacts with a novel stress-inducible complex. Nucleic Acids Res. 27: 1437-1443.

Roy, B., W.W. Li, and A.S. Lee. 1996. Calcium-sensitive transcriptional activation of the proximal CCAAT regulatory element of the grp78/BiP promoter by the human nuclear factor CBF/NF-Y. J. Biol. Chem. 271: 28995-29002.

Sachs, A.B., P. Sarnow, and M.W. Hentze. 1997. Starting at the beginning, middle, and end: Translation initiation in eukaryotes. Cell 89: 831-838.

Samuel, C.E., K.L. Kuhen, C.X. George, L.G. Ortega, R. RendeFournier, and H. Tanaka. 1997. The PKR protein kinase-an interferon-inducible regulator of cell growth and differentiation. Int. J. Hematol. 65: 227-237.

Schreck, R., R. Grassmann, B. Fleckenstein, and P.A. Baeuerle. 1992a. Antioxidants selectively suppress activation of NF$\kappa \mathrm{B}$ by human $\mathrm{T}$ - cell leukemia virus type I Tax protein. $J$. Virol. 66: 6288-6293

Schreck, R., B. Meier, D.N. Mannel, W. Droge, and P.A. Baeuerle. 1992b. Dithiocarbamates as potent inhibitors of nuclear factor $\mathrm{\kappa B}$ activation in intact cells. J. Exp. Med. 175: $1181-1194$

Shamu, C.E. and P. Walter. 1996. Oligomerization and phosphorylation of the Irelp kinase during intracellular signaling from the endoplasmic reticulum to the nucleus. $E M B O F$. 15: 3028-3039.

Shen, Y. and T.E. Shenk. 1995. Viruses and apoptosis. Curr. Opin. Genet. Dev. 5: 105-111.

Shi, Y., K.M. Vattem, R. Sood, J. An, J. Liang, L. Stramm, and R.C. Wek. 1998. Identification and characterization of pancreatic eukaryotic initiation factor $2 \alpha$-subunit kinase, PEK, involved in translational control. Mol. Cell. Biol. 18: 74997509.

Shi, Y., J. An, J. Liang, S.E. Hayes, G.E. Sandusky, L.E. Stramm, and N.N. Yang. 1999. Characterization of a mutant pancreatic eIF-2 $\alpha$ kinase, PEK, and co-localization with somatostatin in islet delta cells. J. Biol. Chem. 274: 5723-5730.

Sidrauski, C. and P. Walter. 1997. The transmembrane kinase Irelp is a site-specific endonuclease that initiates mRNA splicing in the unfolded protein response. Cell 90: 1031-1039.

Sidrauski, C., J.S. Cox, and P. Walter. 1996. tRNA ligase is re- 
quired for regulated mRNA splicing in the unfolded protein response. Cell 87: 405-413.

Silberstein, S., G. Schlenstedt, P. Solver, and R. Gilmore. 1998. A role for the DnaJ homolog Scjlp in protein folding in the yeast endoplasmic reticulum. J. Cell. Biol. 143: 921-933.

Sok, J., X.Z. Wang, N. Batchvarova, M. Kuroda, H. Harding, and D. Ron. 1999. CHOP-dependent stress-inducible expression of a novel form of carbonic anhydrase VI. Mol. Cell. Biol. 19: 495-504.

Sonenberg, N. 1994. mRNA translation: Influence of the $5^{\prime}$ and 3' untranslated regions. Curr. Opin. Genet. Dev. 4: 310-315.

Sonenberg, N. and A.C. Gingras. 1998. The mRNA 5' cap-binding protein eIF4E and control of cell growth. Curr. Opin. Cell. Biol. 10: 268-275.

Srinivasan, M., N. Lenny, and M. Green. 1993. Identification of genomic sequences that mediate the induction of the endoplasmic reticulum stress protein, ERp72, by protein traffic. DNA Cell. Biol. 12: 807-822.

Srivastava, S.P., K.U. Kumar, and R.J. Kaufman. 1998. Phosphorylation of eukaryotic translation initiation factor 2 mediates apoptosis in response to activation of the doublestranded RNA-dependent protein kinase. I. Biol. Chem. 273: 2416-2423.

Srivastava, S.P., M.V. Davies, and R.J. Kaufman. 1995. Calcium depletion from the endoplasmic reticulum activates the double-stranded RNA-dependent protein kinase (PKR) to inhibit protein synthesis. J. Biol. Chem. 270: 16619-16624.

St. Johnston, D., N.H. Brown, J.G. Gall, and M. Jantsch. 1992. A conserved double-stranded RNA-binding domain. Proc. Nat1. Acad. Sci. 89: 10979-10983.

Sugawara, S., K. Takeda, A. Lee, and G. Dennert. 1993. Suppression of stress protein GRP78 induction in tumor B/C10ME eliminates resistance to cell mediated cytotoxicity. Cancer Res. 53: 6001-6005.

Sunnerhagen, M., S. Forsen, A.M. Hoffren, T. Drakenberg, O. Teleman, and J. Stenflo. 1995. Structure of the Ca(2+)-free Gla domain sheds light on membrane binding of blood coagulation proteins. Nat. Struct. Biol. 2: 504-509.

Takewaka, T., T. Zimmer, A. Hirata, A. Ohta, and M. Takagi. 1999. Null mutation in IRE1 gene inhibits overproduction of microsomal cytochrome P450Alk1 (CYP 52A3) and proliferation of the endoplasmic reticulum in Saccharomyces cerevisiae. J. Biochem. (Tokyo) 125: 507-514.

Takizawa, T., K. Ohashi, and Y. Nakanishi. 1996. Possible involvement of double-stranded RNA-activated protein kinase in cell death by influenza virus infection. J. Virol. 70: 81288132 .

Tam, S.S., D.H. Lee, E.Y. Wang, D.G. Munroe, and C.Y. Lau. 1995. Tepoxalin, a novel dual inhibitor of the prostaglandin-H synthase cyclooxygenase and peroxidase activities. $I$. Biol. Chem. 270: 13948-13955.

Thomas, P.J., B.H. Qu, and P.L. Pedersen. 1995. Defective protein folding as a basis of human disease. Trends Biochem. Sci. 20: 456-459.

Thomis, D.C. and C.E. Samuel. 1992. Mechanism of interferon action: Autoregulation of RNA-dependent P1/eIF- $2 \alpha$ protein kinase (PKR) expression in transfected mammalian cells. Proc. Natl. Acad. Sci. 89: 10837-10841.

Tirasophon, W., A.A. Welihinda, and R.J. Kaufman. 1998. A stress response pathway from the endoplasmic reticulum to the nucleus requires a novel bifunctional protein kinase/ endoribonuclease (Ire1p) in mammalian cells. Genes \& Dev. 12: $1812-1824$.

Trombetta, S.E. and A.J. Parodi. 1992. Purification to apparent homogeneity and partial characterization of rat liver UDPglucose:glycoprotein glucosyltransferase. I. Biol. Chem.
267: 9236-9240.

Trotta, C.R., F. Miao, E.A. Arn, S.W. Stevens, C.K. Ho, R. Rauhut, and J.N. Abelson. 1997. The yeast tRNA splicing endonuclease: A tetrameric enzyme with two active site subunits homologous to the archaeal tRNA endonucleases. Cell 89: 849-858.

Tsuiki, S., A. Hiraga, K. Kikuchi, and S. Tamura. 1988. Purification of an $\mathrm{Mg} 2+-$ dependent protein phosphatase. Methods Enzymol. 159: 437-446.

Van Antwerp, D.J., S.J. Martin, T. Kafri, D.R. Green, and I.M. Verma. 1996. Suppression of TNF- $\alpha$-induced apoptosis by NF-кB. Science 274: 787-789.

Wang, C.Y., M.W. Mayo, and A.S. Baldwin, Jr. 1996. TNF- and cancer therapy-induced apoptosis: Potentiation by inhibition of NF-kappaB. Science 274: 784-787.

Wang, X.Z. and D. Ron. 1996. Stress-induced phosphorylation and activation of the transcription factor CHOP (GADD153) by p38 MAP kinase. Science 272: 1347-1349.

Wang, X.Z., B. Lawson, J.W. Brewer, H. Zinszner, A. Sanjay, L.J. Mi, R. Boorstein, G. Kreibich, L.M. Hendershot, and D. Ron. 1996. Signals from the stressed endoplasmic reticulum induce C/EBP-homologous protein (CHOP/GADD153). Mol. Cell. Biol. 16: 4273-4280.

Wang, X.Z., H.P. Harding, Y. Zhang, E.M. Jolicoeur, M. Kuroda, and D. Ron. 1998a. Cloning of mammalian Ire1 reveals diversity in the ER stress responses. EMBO J. 17: 5708-5717.

Wang, X.Z., M. Kuroda, J. Sok, N. Batchvarova, R. Kimmel, P. Chung, H. Zinszner, and D. Ron. 1998b. Identification of novel stress-induced genes downstream of chop. EMBO $J$. 17: 3619-3630.

Ward, C.L., S. Omura, and R.R. Kopito. 1995. Degradation of CFTR by the ubiquitin-proteasome pathway. Cell 83: 121127.

Wearsch, P.A. and C.V. Nicchitta. 1997. Interaction of endoplasmic reticulum chaperone GRP94 with peptide substrates is adenine nucleotide-independent. J. Biol. Chem. 272: 5152-5156.

Welihinda, A.A. and R.J. Kaufman. 1996. The unfolded protein response pathway in Saccharomyces cerevisiae. Oligomerization and trans-phosphorylation of Irelp (Ernlp) are required for kinase activation. J. Biol. Chem. 271: 18181-18187.

Welihinda, A.A., W. Tirasophon, S.R. Green, and R.J. Kaufman. 1997. Gene induction in response to unfolded protein in the endoplasmic reticulum is mediated through Irelp kinase interaction with a transcriptional coactivator complex containing Ada5p. Proc. Natl. Acad. Sci. 94: 4289-4294.

Welihinda, A.A., W. Tirasophon, S.R. Green, and R.J. Kaufman. 1998. Protein serine/threonine phosphatase Ptc2p negatively regulates the unfolded-protein response by dephosphorylating Irelp kinase. Mol. Cell. Biol. 18: 1967-1977.

White, M.J., J.P. Hirsch, and S.A. Henry. 1991. The OPI1 gene of Saccharomyces cerevisiae, a negative regulator of phospholipid biosynthesis, encodes a protein containing polyglutamine tracts and a leucine zipper. J. Biol. Chem. 266: 863872.

Wiest, D.L., J.K. Burkhardt, S. Hester, M. Hortsch, D.I. Meyer, and Y. Argon. 1990. Membrane biogenesis during B cell differentiation: Most endoplasmic reticulum proteins are expressed coordinately. J. Cell. Biol. 110: 1501-1511.

Woronicz, J.D., X. Gao, Z. Cao, M. Rothe, and D.V. Goeddel. 1997. ІкB kinase- $\beta$ : NF- $\kappa$ B activation and complex formation with IкB kinase- $\alpha$ and NIK. Science 278: 866-869.

Wu, S., K.U. Kumar, and R.J. Kaufman. 1998. Identification and requirement of three ribosome binding domains in dsRNA-dependent protein kinase (PKR). Biochemistry 37: 
$13816-13826$.

Wu, Y., I. Whitman, E. Molmenti, K. Moore, P. Hippenmeyer, and D.H. Perlmutter. 1994. A lag in intracellular degradation of mutant alpha 1-antitrypsin correlates with the liver disease phenotype in homozygous PiZZ $\alpha$ 1-antitrypsin deficiency. Proc. Nat1. Acad. Sci. 91: 9014-9018.

Yoshida, H., K. Haze, H. Yanagi, T. Yura, and K. Mori. 1998. Identification of the cis-acting endoplasmic reticulum stress response element responsible for transcriptional induction of mammalian glucose-regulated proteins. Involvement of basic leucine zipper transcription factors. J. Biol. Chem. 273: 33741-33749.

Zandi, E., D.M. Rothwarf, M. Delhase, M. Hayakawa, and M. Karin. 1997. The ІкB kinase complex (IKK) contains two kinase subunits, IKK $\alpha$ and IKK $\beta$, necessary for IкB phosphorylation and NF-кB activation. Cell 91: 243-252.

Zhan, Q., K.A. Lord, I. Alamo, Jr., M.C. Hollander, F. Carrier, D. Ron, K.W. Kohn, B. Hoffman, D.A. Liebermann, and A.J. Fornace, Jr. 1994. The gadd and MyD genes define a novel set of mammalian genes encoding acidic proteins that synergistically suppress cell growth. Mol. Cell. Biol. 14: 2361-2371.

Zhu, X., X. Zhao, W.F. Burkholder, A. Gragerov, C.M. Ogata, M.E. Gottesman, and W.A. Hendrickson. 1996. Structural analysis of substrate binding by the molecular chaperone DnaK. Science 272: 1606-1614.

Zinn, K., A. Keller, L.A. Whittemore, and T. Maniatis. 1988. 2 -Aminopurine selectively inhibits the induction of $\beta$-interferon, c-fos, and c-myc gene expression. Science 240: 210 213.

Zinszner, H., M. Kuroda, X. Wang, N. Batchvarova, R.T. Lightfoot, H. Remotti, J.L. Stevens, and D. Ron. 1998. CHOP is implicated in programmed cell death in response to impaired function of the endoplasmic reticulum. Genes \& Dev. 12: 982-995. 


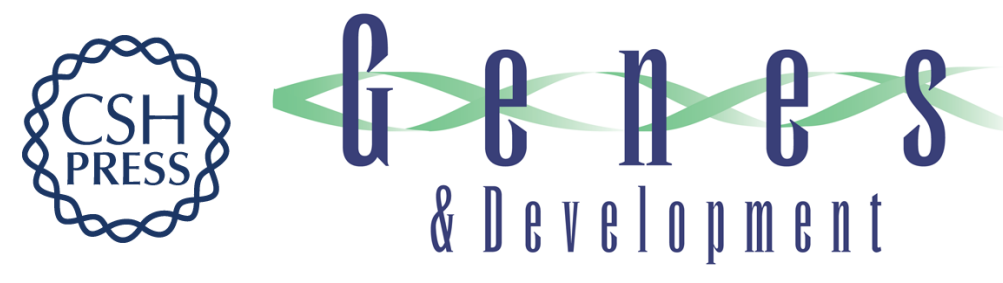

\section{Stress signaling from the lumen of the endoplasmic reticulum: coordination of gene transcriptional and translational controls}

Randal J. Kaufman

Genes Dev. 1999, 13:

\section{Related Content Errata for vol.13, p.1211 \\ Genes Dev. July , 1999 13: 1898}

References This article cites 186 articles, 98 of which can be accessed free at: http://genesdev.cshlp.org/content/13/10/1211.full.html\#ref-list-1

Articles cited in:

http://genesdev.cshlp.org/content/13/10/1211.full.html\#related-urls

\section{License}

Email Alerting

Service

Receive free email alerts when new articles cite this article - sign up in the box at the top right corner of the article or click here.

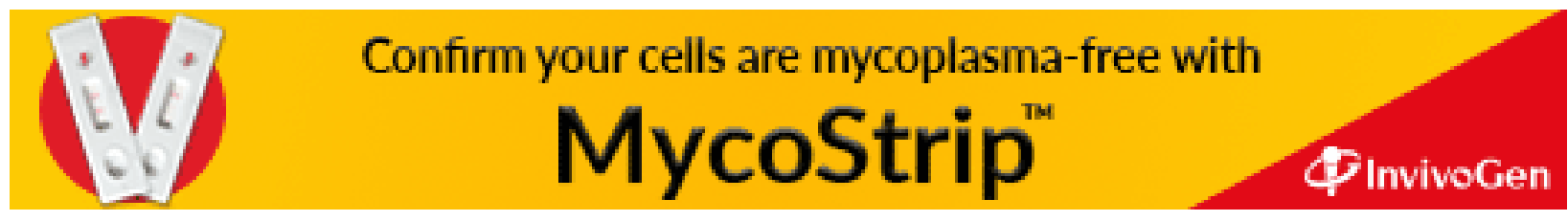

